Tests were conducted to improve the formulation of maleic hydrazide (MH) with respect to absorption and to add to its lethal action. It was found that surfactants and humectants intensify the effects of MH, that water-soluble forms are more effective than oil carriers, and that high humidity promotes absorption. Effectiveness, as judged by extent of regrowth, was also increased somewhat by after-treatments with toxic aromatic oils, repeated sprays of $\mathbf{M H}$, follow-up applications of sodium chlorate, and simulated tillage treatments performed several days after spraying. Disturbance of plants two months after treatment, however, seemed to break dormancy. MH-induced dormancy was more prolonged in old, well-established Bermudagrass cultures than in new ones; however, MH sprays on annual grass cultures at different stages of maturity proved that young plants showed more injury than old ones.

The research with labeled compounds reported in this paper was made possible by A.E.C. Contract AT(11-1)-34 Project No. 9. 


\begin{tabular}{|c|c|c|}
\hline & $\begin{array}{l}\text { A Journal of Agricultural Science Published by } \\
\text { the California Agricultural Experiment Station }\end{array}$ & \\
\hline VoL. 27 & OCTOBER, 1958 & No. 22 \\
\hline
\end{tabular}

\section{SOME STUDIES ON THE HERBICIDAL PROPERTIES OF MALEIC HYDRAZIDE ${ }^{1}$}

\section{A. S. CRAFTS, H. B. CURRIER, and H. R. DREVER ${ }^{2}$}

\section{INTRODUCTION}

Maleic hydrazide (MH) was first described as a growth regulator and inhibitor (Schoene and Hoffman, 1949). Very soon its inhibiting effect on young grass plants suggested use as a herbicide (Currier and Crafts, 1950). Since then many publications have described its use to inhibit growth, control sprouting, eliminate bolting, break apical dominance, and produce male sterility (Zukel, 1954).

After seven years of testing, a number of practical applications of this chemical have been made. Prominent among these are its use in inhibiting sprouts on topped tobacco plants (Anon., 1955b) and its effective control of quackgrass in the midwest (Buchholtz, 1954). In the latter case, treatment with 8 pounds of the chemical in 20 gallons of water per acre, followed by plowing in seven days, produced excellent control.

In treating quackgrass it is best to allow the plants to grow in the spring until the foliage is 6 to 10 inches high, to use a surfactant and a humectant in the spray, and to plant the sprayed area and cultivate it periodically to keep down seedling weed growth. In analyzing this method it should be apparent that the use of a humectant aids in the absorption of the chemical; growth of the plants is such that adequate translocation takes place within the plant; and the tillage operations upset the metabolism of the grass and prevent its re-establishment. In short, formulation and spray practice have been designed to foster uptake and distribution of the chemical; cultural treatments have been added that supplement the prolonged dormancy with the final result of death. Since the chemical is applied to the leaves, its action is evidently physiological through the plant; the soil is free of the chemical and favorable for crop production (fig. 1).

\footnotetext{
${ }^{1}$ Received for publication May 29, 1957.

${ }^{2} \mathrm{Mr}$. Crafts is Professor of Botany and Botanist in the Experiment Station, Davis; Mr. Currier is Professor of Botany and Botanist in the Experiment Station, Davis; Mr. Drever is Senior Laboratory Technician in the Department of Botany, Davis.
} 
A third practical use is in the control of wild onions and garlic. In the southern and central eastern states, where they are common, MH is effectively eliminating these pests from pastures and fields (Harris et al., 1954). Despite these three very definite uses of $\mathrm{MH}$, this interesting chemical has not proved to be the effective herbicide that the early tests seemed to indicate it would.

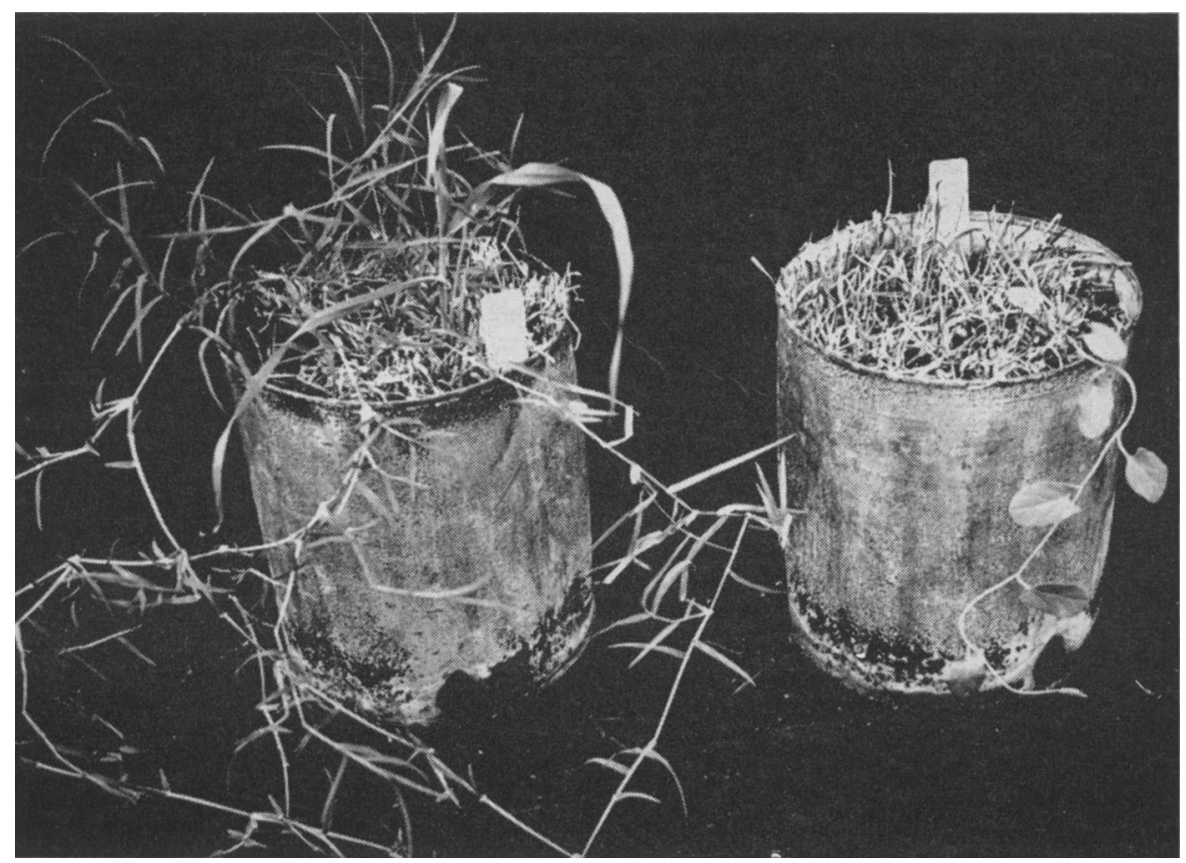

Fig. 1. Two Bermudagrass cultures sprayed with 0.8 per cent (left) and 1.6 per cent (right) $\mathrm{MH}$ as the diethanolamine salt on July 6, 1950. The photograph was taken on April 4, 1951, and it shows that the culture on the right is still dormant, whereas that on the left is starting to grow. Note the healthy barley plant growing in the soil of the culture on the left, and the wild morning-glory seedling growing in the right-hand culture. This is evidence that there is no $\mathrm{MH}$ residue in the soil of these cultures.

Why has so promising a chemical not found wider use? Two rather prominent characteristics may be pointed out in this connection. First, the most outstanding property of $\mathrm{MH}$ is its ability to induce a deep and lasting dormancy in perennial structures. As far as grasses are concerned, it is easy to mistake this dormancy for death and so to assign to the chemical a high toxicity. However, in the case of perennial grasses, the plants often recover and grow vigorously even a year or more after the initial treatment. The very characteristic that makes $\mathrm{MH}$ a good sprout inhibitor and growth regulator militates against its herbicidal use.

Second, like many chemicals, MH shows definite selectivities with respect to its herbicidal action. Grasses in general are killed, particularly in their seedling stages; however, there are wide differences in susceptibility. With broad-leafed plants there is also a wide range of specificity in action. How- 
ever, the chemical inhibits growth in most plants so that it cannot be used effectively as a true selective herbicide.

As with many of the new chemicals, time will be required to find all of the special uses for MH. The experiments described herein have been designed to improve $\mathrm{MH}$ formulation with respect to absorption and to add to its lethal action.

\section{MATERIALS AND METHODS}

Test plants (bean, barley, Bermudagrass, etc.) were grown in the greenhouse and at stipulated times sprayed with or dipped in $\mathrm{MH}$ solutions or treated by applying drops. Formative effects, growth inhibition, and lethal action were recorded, usually over extended periods of time. Finally, $\mathrm{C}^{14}$-labeled MH was applied to leaves in accurately measured amounts by micropipette; after prescribed treatment periods the plants were killed and freeze-dried; autoradiographs were prepared that showed the distribution of the tracer.

\section{RESULTS}

\section{Interaction of $\mathrm{MH}$ and 2,4-D}

In 1951 we reported that MH interferes with the bending of the bean epicotyl that results from 2,4-D treatment (Currier, Day, and Crafts, 1951). Table 1 presents data from three experiments, the original one reported in

TABLE 1

EFFECT OF MH ON BENDING OF BEAN EPICOTYLS TREATED WITH 2,4-D (Data are degrees curvature in the direction of the arrow)

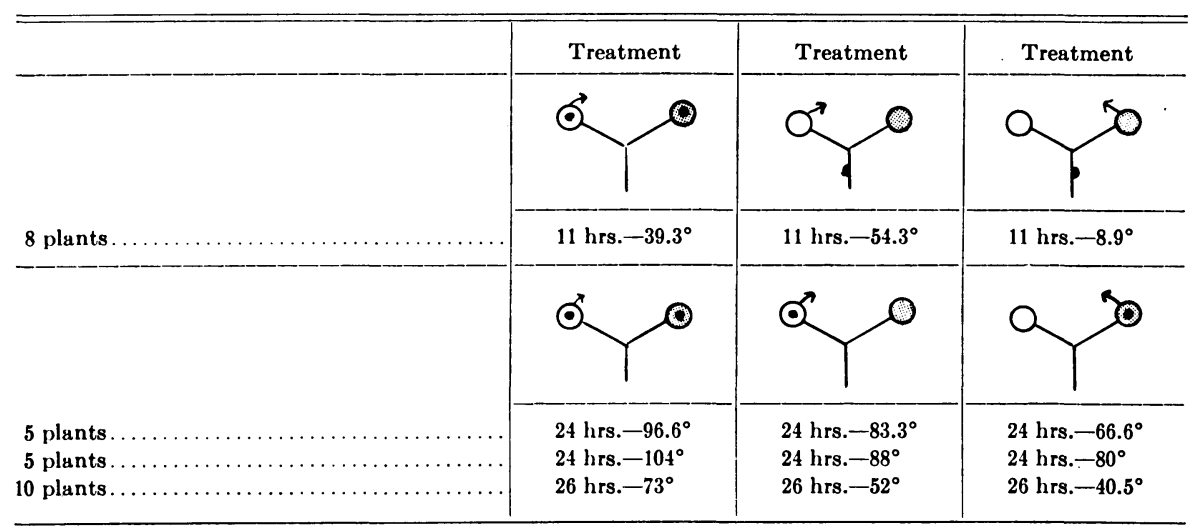

$\bigcirc$ untreated leaf; $\odot 2,4-\mathrm{D} ; \mathrm{MH} ; \bigcirc 2,4-\mathrm{D}$ plus $\mathrm{MH}$ applied to leaf; $\{2,4-\mathrm{D}$ applied to stem; $\uparrow$ direction of bending.

1951 and two additional ones. MH alone caused no bending, and applied in combination with 2,4-D it tended to restrict bending.

These results indicate that though the differences in bending may not be great, they are consistent. They would seem to imply an inhibition of growth in the epicotyl rather than a restriction of translocation. Results with labeled MH, to be reported later, are in agreement with this explanation.

Trials with combinations of $\mathrm{MH}$ and 2,4-D on Bermudagrass failed to give 
significant indications of interaction, a result probably related to the known selectivities of these chemicals on perennial grasses.

\section{Role of Ultraviolet Light in MH Breakdown}

Following the original announcement of the possible herbicidal effectiveness of MH (Currier and Crafts, 1950) many field trials were made. Under California conditions these were in general disappointing, and so some reason was sought for the differences observed between greenhouse and field results. One suggestion was that $\mathrm{MH}$ was possibly decomposed by ultraviolet light in the sunlight to which the spray solution on the plants was exposed. To test this idea, $\mathrm{MH}$ solutions were prepared and exposed to daylight in the greenhouse for 7 days and to daylight outside the greenhouse for 1 day, 2 days, and 7 days; control solutions were kept in the dark. The solutions were sprayed on 20-day-old barley plants (var. Sacramento). No significant differences were found. All sprayed plants showed clear MH-inhibition symptoms and failed to head. Control (unsprayed) plants were normal and headed in the usual way. Evidently the differences were not caused by the effect of light on the MH.

\section{Foliage- vs. Soil-Applied MH}

In the growing and treatment of greenhouse plants, unless watering is very carefully done the chemical may be washed from sprayed plants into the soil whence it is absorbed by roots and distributed throughout the tops. To determine the quantity of foliage-applied $\mathrm{MH}$ required to produce the effects on barley obtained by soil application, 20-day-old barley plants were sprayed with 20 ec of 0.2 per cent $\mathrm{MH}$ per culture; similar cultures were treated by pouring an equal quantity of this $\mathrm{MH}$ solution on the soil around the base of the plants and washing it in by watering. Care was taken to avoid washing MH from the sprayed plants into the soil and, also, to avoid loss from the soil by leaching in the case of the soil applications.

Growth inhibition was observed in all cases, and no significant differences were found between treatment through foliage and through the roots. This is in contradiction to results of Schoene and Hoffman (1949), who reported that more chemical was required for soil application. However, this could well have been the result of using different soil types. Levi and Crafts (1952; see figs. 1-11) have shown rather large differences between soils with respect to their ability to render $\mathrm{MH}$ nontoxic to plants.

\section{Tests on Formulation}

In the next experiment 23 formulations of $\mathrm{MH}(\mathrm{MH}, 0.5$ per cent active basis) were applied to Bermudagrass cultures in the greenhouse on March 22,1950 . Some of the $\mathrm{MH}$ compounds were insoluble in water, and these were applied as suspensions kept in constant agitation to insure applicition of the solid phase. The salt of diethanolamine (DEA), supplied as MH-30, was combined with a number of penetrants, humectants, and mild toxicants. With a few exceptions, as indicated in table 2, all solutions contained Vatsol OT at 0.1 per cent.

Nine weeks after spraying the degree of injury to sprayed foliage was observed and estimated in terms of percentage, 100 per cent indicating 
complete inhibition, 0 per cent no inhibition. The amount of regrowth and the presence of flowers were recorded 16 weeks after spraying. The results are shown in table 2. Figures 2 and 3 show some of the cultures photographed July 11, 1950.

On March 16, 1951, a year after the treatments, all cultures had made some regrowth, but two remained clearly inhibited. Those treated with DEA in 5 per cent aqueous glycerine showed only 25 per cent regrowth; cultures treated with DEA dissolved in 95 per cent ethanol showed regrowth in only 50 per cent of the shoots.

TAPLE 2

MH FORMULATIONS RATED ACCORDING TO THE AMOUNT OF REGROWTH SHOWN BY BERMUDAGRASS CULTURE'S

\begin{tabular}{|c|c|c|c|}
\hline Formulation* & Necrosist & Regrowth $\ddagger$ & Flowering $\ddagger$ \\
\hline & per cent & & \\
\hline MH, diethanoleamine salt, in $95 \%$ ethanol. & 85 & None & 0 \\
\hline MH, diethanoleamine salt, in $5 \%$ glycerine..... & 70 & None & 0 \\
\hline MH, diethanoleamine salt, in $5 \%$ Triton B-1956... & 95 & Trace & 0 \\
\hline $\mathrm{MH}$, diethanoleamine salt, in $0.16 \%$ benzene..... & 75 & Very slight & 0 \\
\hline MH, diethanoleamine salt.......... & 70 & Slight & 0 \\
\hline $\mathrm{N}$-acetyl $\mathrm{MH} \ldots \ldots \ldots \ldots$ & 65 & Slight & 0 \\
\hline MH, diethanoleamine salt, in $1 \% \mathrm{KCNS} \ldots$ & 60 & Slight & 0 \\
\hline MH technical ....................... & 60 & Moderate & 0 \\
\hline 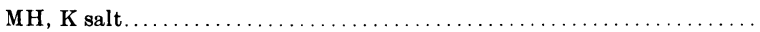 & 60 & Moderate & 0 \\
\hline MH, dodecylamine salt... & 60 & Moderate & + \\
\hline MH, Na salt............... & 60 & Moderate & 0 \\
\hline MH, Mn salt $\ldots \ldots \ldots \ldots \ldots \ldots \ldots \ldots \ldots \ldots \ldots \ldots \ldots \ldots \ldots$ & 60 & Dense & + \\
\hline 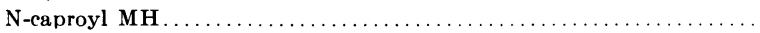 & 40 & Dense & + \\
\hline 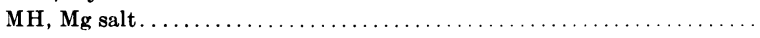 & 40 & Dense & + \\
\hline 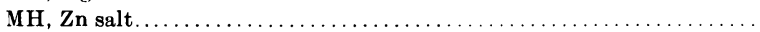 & 40 & Dense & + \\
\hline N-benzoyl MH. & 30 & Dense & + \\
\hline $\mathrm{MH}$, diethanoleamine salt, in $50 \%$ glycerine & 25 & Mod.-dense & + \\
\hline $\mathrm{MH}, \mathrm{Al}$ salt $\ldots \ldots \ldots \ldots \ldots \ldots \ldots \ldots \ldots \ldots$ & 25 & Dense & + \\
\hline MH, Ca salt................... & 20 & Mod.-dense & + \\
\hline MH, Cu salt.............. & 10 & Dense & + \\
\hline MH technical, no Vatsol. & 10 & Dense & + \\
\hline 2-ethyl hexoyl MH..... & 0 & Dense & + \\
\hline N-benzoyl MH, no Vatsol. & 0 & Dense & + \\
\hline Control................ & 0 & Dense & + \\
\hline
\end{tabular}

$0=$ no flowers, $+=$ some flowers present.

* Spray applizd March 22. 1950. MH was applied at 0.5 per cent active basis in all instances. All solutions except those noted contained Vatsol OT at 0.1 per cent.

Data taken May 24, 1950.

† Data taken July 11. 1950 .

These results indicate that of the compounds tested, the diethanolamine salt is the most effective, that 0.1 per cent Vatsol increases the effectiveness, that 95 per cent ethanol as a solvent was surprisingly effective, and that glycerine and Triton B-1956 also increased the toxic action. The improvement is interpreted as due to both humectant and surfactant properties of the additives, which promote penetration of $\mathrm{MH}$.

The insoluble salts of MH were ineffective. This is in distinct contrast to the dinitro compounds and 2,4-D acid, all of which are readily absorbed from the suspended form.

Bermudagrass was retarded in growth for over a year by these treatments, 
[Vol. 27, No. 22

but killing was not complete; resprouts from the plants eventually were normal and healthy.

Humectant Effects. As shown by Zukel et al. (1956), humidity or humectants are important in promoting penetration of MH. Humectants probably act in two principal ways: 1) they prevent drying of spray solution on the leaf surface, and 2) they become sorbed by cuticle, thus increasing the polar

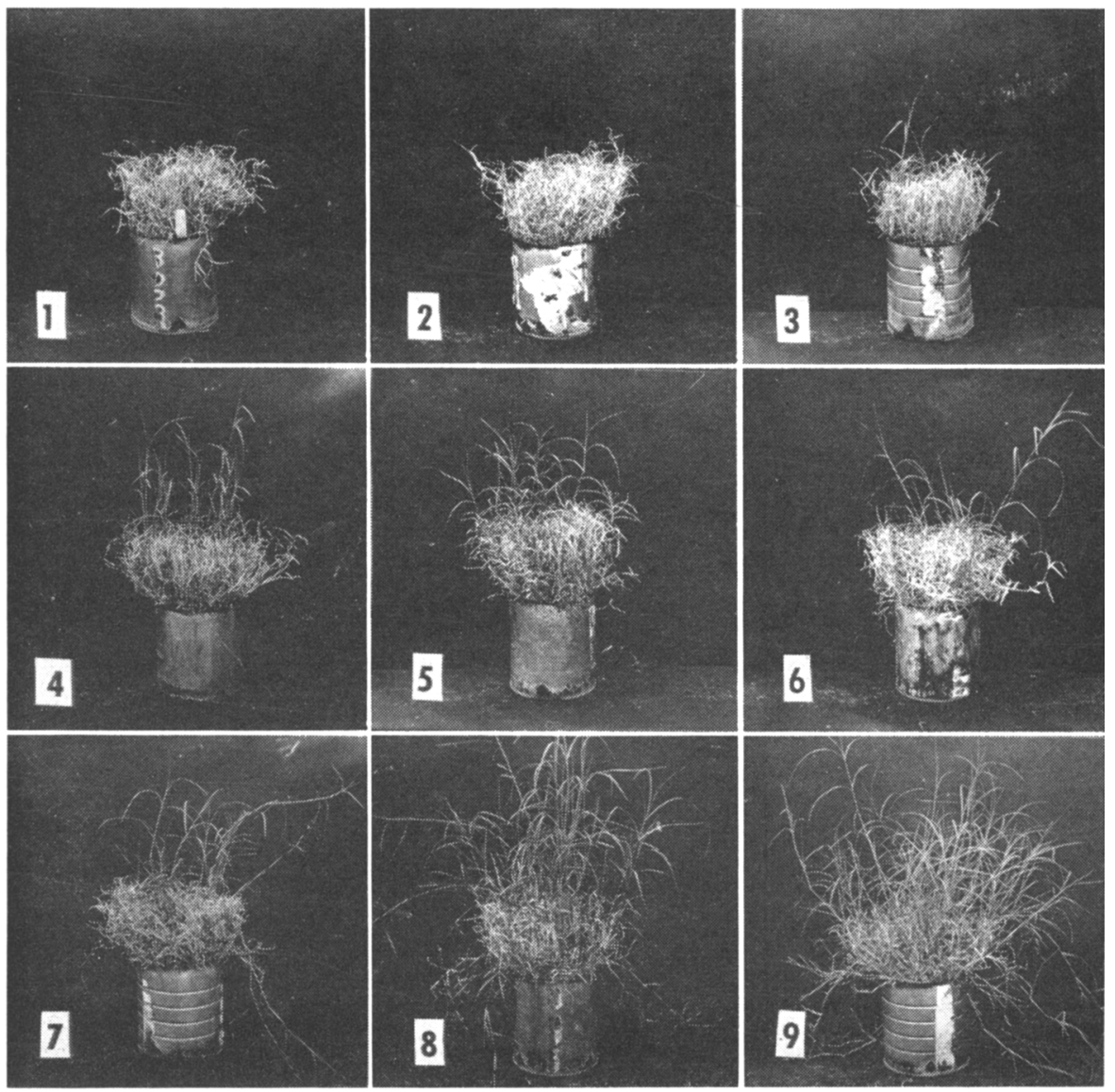

Fig. 2. Bermudagrass cultures sprayed with $\mathrm{MH}$ formulations 1 to 9 (table 2), arranged in the same order of increasing resprouting response. The cultures were sprayed March 22,1950 , and photographed July 11, 1950.

nature of the cuticle and its compatibility with water-soluble chemicals like MH. Glycerine must act in this way; Vatsol, Triton B-1956, and diethanolamine must also exhibit some humectant effects. The lower effectiveness of the 50 per cent glycerine as compared with the 5 per cent may have resulted from a toxic dehydration that hindered absorption and translocation.

Surfactant Effects. Surfactant materials, like Vatsol, Triton B-1956, and ethanol, probably improve penetration by 1) increasing the area of 
contact between cuticle and spray solution by means of lowering the interfacial tension and eliminating air films; 2) acting as cuticular penetrants, possibly reducing the interfacial tension between submicroscopic polar and apolar regions in cuticle; and 3) inducing stomatal entry to some extent.

pH Effects. Evidently MH does not follow the rules established for dinitro compounds and the chlorophenoxy compounds (Anon, 1955a). This conclusion was further substantiated by an experiment involving a $\mathrm{pH}$ series with

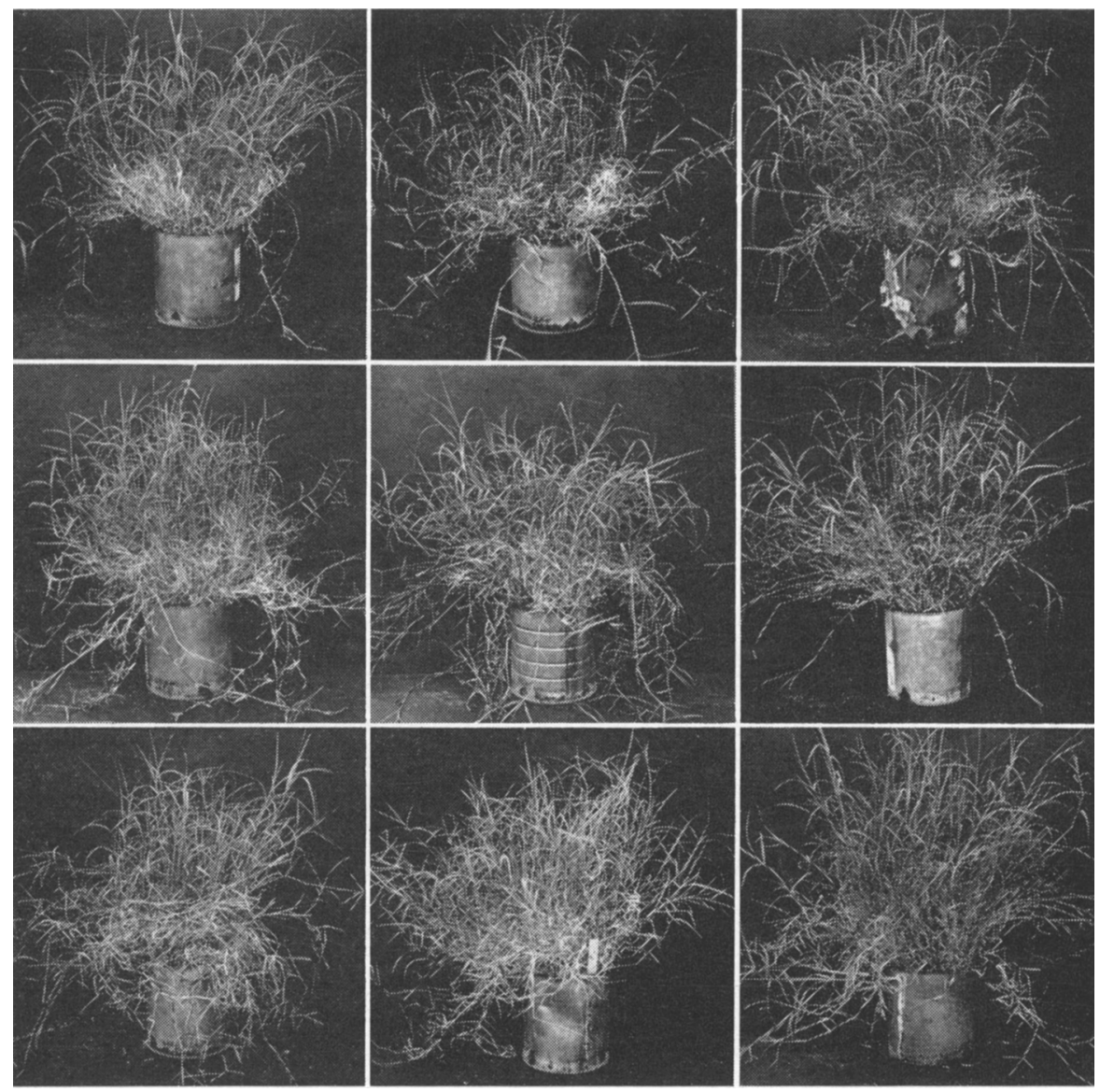

Fig. 3. Bermudagrass cultures sprayed with MH formulations 10, 11, 13, 16, 17, 19, 21, 23, and 24 (table 2) and arranged in the same order of increasing resprouting response. The cultures were sprayed March 22, 1950, and photographed July 11, 1950.

0.5 per cent $\mathrm{MH}$ (as DEA) on Bermudagrass. Sprays were first applied on January 11, 1951, to duplicate cultures. Notes were taken five times during the spring, and the top growth was harvested and weighed on six subsequent dates. Table 3 presents the data on these weighings. If the average weights of growth for the six readings (column 8 , table 3 ) are plotted against $\mathrm{pH}$ values, the points fit a normal distribution curve with the minimum growth (maximum inhibition) at $\mathrm{pH} 7$. 
A second test on the relation of $\mathrm{pH}$ to effectiveness of $\mathrm{MH}$, using a 2.0 per cent solution of $\mathrm{MH}$ (DEA salt) plus 0.1 per cent Multifilm L as a wetting agent, and with sprays adjusted to $\mathrm{pH} 6,7,8$, and 9, produced minimum growth at $\mathrm{pH} 8$ after 11 months. These results, coupled with those comparing straight $\mathrm{MH}$ with its diethanolamine salt, prove that in contrast to the dinitro compounds and the chlorophenoxyacetic acid derivatives, $\mathrm{MH}$ penetration is best when the chemical is applied as a water-soluble salt at $\mathrm{pH}$ 7. As mentioned, high humidity and humectants greatly increase $\mathrm{MH}$ absorption by plants (Zukel, 1956).

\section{TABLE 3}

WEIGHT IN GRAMS OF GROWTH OF BERMUDAGRASS SHOOTS SPRAYED

JANUARY 11, 1951, WITH 0.5 PER CENT MH (DEA) ADJUSTED TO A SERIES OF PH VALUES

(Values are averages of duplicate cultures)

\begin{tabular}{|c|c|c|c|c|c|c|c|}
\hline \multirow{2}{*}{$\mathrm{pH}$} & \multicolumn{6}{|c|}{ Harvest dates } & \multirow{2}{*}{ Average } \\
\hline & $7 / 3 / 51$ & $9 / 25 / 51$ & $12 / 3 / 51$ & $3 / 7 / 52$ & $7 / 23 / 52$ & $9 / 2 / 52$ & \\
\hline Control. & 51.5 & 81.9 & 12.5 & 14.0 & 242 & 10.0 & 32.3 \\
\hline $2 \ldots$ & 16.7 & 59.0 & 15.2 & 18.2 & 22.2 & 9.5 & 23.9 \\
\hline 3. & 17.1 & 58.0 & 15.4 & 18.5 & 19.2 & 8.0 & 22.7 \\
\hline $4 \ldots \ldots$ & 18.5 & 40.2 & 16.6 & 25.3 & 22.0 & 8.6 & 21.9 \\
\hline $5 \ldots \ldots \ldots$ & 19.5 & 18.7 & 11.7 & 21.3 & 28.3 & 8.6 & 18.0 \\
\hline $6 \ldots \ldots$ & 17.1 & 7.7 & 7.9 & 9.3 & 10.9 & 3.9 & 9.5 \\
\hline $7 \ldots$ & 13.9 & 70 & 59 & 0.0 & 0.0 & 0.0 & 45 \\
\hline $8 \ldots \ldots \ldots$ & 15.8 & 06 & 7.9 & 14.0 & 15.5 & 4.1 & 97 \\
\hline $9 \ldots \ldots \ldots$ & 20.2 & 25.2 & 19.3 & 24.7 & 27.9 & 11.6 & 21.5 \\
\hline $10 \ldots \ldots \ldots \ldots$ & 18.5 & 37.1 & 11.6 & 13.7 & 31.8 & 10.6 & 20.6 \\
\hline
\end{tabular}

Additional Formulation Trials. Further experiments were run with MH on Bermudagrass grown in the greenhouse to test a number of formulations for effectiveness in inhibiting Bermudagrass growth. The shoots of established duplicate cultures in gallon cans were clipped to uniform length, and the cultures were then sprayed to near run-off ( $5 \mathrm{ml}$ per plant) with 1 per cent MH (DEA salt) solutions containing various additives. In one instance the $\mathrm{MH}$ concentration was 0.5 per cent. The $\mathrm{pH}$ values and leafwetting power were noted. The $\mathrm{pH}$ values, with two exceptions, lay between 7.5 and 7.9 ; the two solutions containing borax had a pH of 8.1. Observations were made only at the time of harvest, 17 weeks after treatment. Height, regrowth, and amount of necrosis of treated leaves were recorded.

Surfactants that showed promise in earlier tests were used: Vatsol OT, Tween 20, Tergitol XC dioleate, Tergitol TMN 650, Atlas 1096, Multifilm LPB, and Triton X-100. Propylene glycol was added for its humectant effect. Carbowax 4000, Carbowax 1500, and Methocel were used as deposit builders. Oils were used both as a follow-up treatment (paraffinol) and as a diluent (Dispersol). Urea and borax, reported by other workers to be active in some way in promoting penetration of herbicides, were used as additives in aqueous solutions of MH. Ethanol (at 95 per cent) gave good results as a solvent in earlier tests. Dalapon and endothal were included to note any synergistic or antagonistic effects. Table 4 presents the data on this experiment. 


\section{TABLE 4}

\section{RESULTS OF VARIOUS FOLIAGE-SPRAY FORMULATIONS OF MH APPLIED TO BERMUDAGRASS CULTURES}

(Spray applied September 24, 1953; data taken January 20, 1954)

\begin{tabular}{|c|c|c|c|}
\hline Formulation & $\begin{array}{l}\text { Extent of } \\
\text { regrowth* }\end{array}$ & $\begin{array}{l}\text { Av. length } \\
\text { of shoots }\end{array}$ & $\begin{array}{c}\text { Amount of } \\
\text { neerosis } \dagger\end{array}$ \\
\hline & & $\mathrm{cm}$ & \\
\hline MH $1 \%+0.1 \%$ Vatsol OT, when dry sprayed with paraffin oil. . & 0 & 9.5 & 4 \\
\hline MH $1 \%+0.1 \%$ Vatsol OT......... & 0 & 10.0 & 1 \\
\hline MH $1 \%+0.1 \%$ Vatsol OT $+0.1 \%$ Methocel..... & $\mathbf{0}$ & 10.5 & 1 \\
\hline MH $1 \%+0.1 \%$ Vatsol OT $+2 \%$ propylene glycol $+0.1 \%$ benzene..... & 0 & 10.5 & 1 \\
\hline 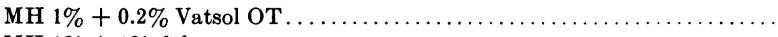 & 0 & 10.5 & 1 \\
\hline 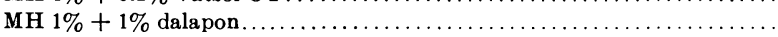 & 0 & 11.0 & 3 \\
\hline MH $1 \%+1 \%$ Atlas G-1096... & 0 & 11.0 & 2 \\
\hline MH $1 \%+0.1 \%$ Tergitol XC-dioleate........... & 0 & 11.0 & 1 \\
\hline MH $1 \%+1 \%$ Tergitol TMN $650 \ldots \ldots \ldots \ldots \ldots$ & 0 & 11.5 & 2 \\
\hline MH $1 \%+0.5 \%$ Vatsol OT $\ldots \ldots \ldots \ldots \ldots \ldots$ & 0 & 11.5 & 1 \\
\hline MH $1 \%+0.1 \%$ Tween $20 \ldots$. & 0 & 11.5 & 1 \\
\hline MH $1 \%+0.1 \%$ Vatsol OT $+1 \%$ Carbowax 4000. & 0 & 11.5 & 1 \\
\hline MH $0.5 \%+0.5 \%$ dalapon. . . & 0 & 11.5 & 1 \\
\hline MH $1 \%+0.1 \%$ Vatsol OT $+0.1 \%$ borax....... & 0 & 12.0 & 1 \\
\hline MH $1 \%+0.1 \%$ Vatsol OT $+1 \%$ Carbowax 1500. & 0 & 12.0 & 1 \\
\hline MH $1 \%+1 \%$ Multifilm LPB $\ldots \ldots \ldots \ldots \ldots \ldots$ & 0 & 12.0 & 1 \\
\hline MH $1 \%+1 \%$ Triton $\mathrm{X}-100 \ldots$ & 0 & 13.5 & 1 \\
\hline MH $1 \%+1 \%$ Carbowax 1500. & 0 & 15.0 & 1 \\
\hline MH $1 \%+0.1 \%$ Tergitol TMN $650 \ldots \ldots \ldots$ & 0 & 15.0 & 1 \\
\hline MH $1 \%+0.1 \%$ Vatsol OT $+5 \%$ ethanol $\ldots$. & 1 & 11.5 & 1 \\
\hline MH $1 \%+0.1 \%$ Triton $\mathrm{X}-100 \ldots \ldots \ldots \ldots \ldots$ & 1 & 11.5 & 1 \\
\hline MH $1 \%+1 \%$ Tween $20 \ldots \ldots$ & 1 & 12.5 & 1 \\
\hline MH $1 \%+1 \%$ Tergitol XC-dioleate. . . . . . . . . . . & 1 & 12.5 & 2 \\
\hline MH $1 \%+0.1 \%$ Vatsol OT $+2 \%$ propylene glycol............... & 1 & 13.5 & 1 \\
\hline 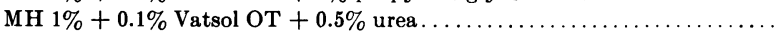 & 1 & 13.5 & 1 \\
\hline 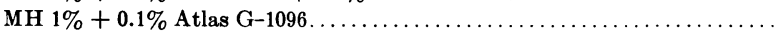 & 1 & 14.0 & 2 \\
\hline MH $1 \%+1 \%$ Carbowax $4000 \ldots \ldots \ldots \ldots \ldots \ldots \ldots$ & 1 & 15.0 & 1 \\
\hline MH $1 \%+0.1 \%$ Multifilm LPB. & 1 & 15.5 & 1 \\
\hline MH $1 \%+2 \%$ propylene glycol......... & 2 & 11.0 & 2 \\
\hline MH $1 \%+0.5 \%$ urea.............. & 2 & 13.5 & 1 \\
\hline MH $1 \%$ alone................ & 2 & 13.5 & 1 \\
\hline MH $1 \%+0.1 \%$ dalapon...... & 2 & 15.0 & 2 \\
\hline $\mathrm{MH} 1 \%+5 \%$ ethanol... & 2 & 33.0 & 2 \\
\hline MH $1 \%+0.1 \%$ Vatsol OT (Dispersol as solvent) & 3 & 43.5 & $\ddagger$ \\
\hline 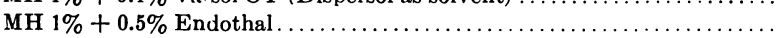 & 3 & 44.0 & $\ddagger$ \\
\hline MH $1 \%+0.1 \%$ borax..... & 3 & 44.5 & 3 \\
\hline Checks-untreated.... & 4 & 45.0 & 0 \\
\hline MH $1 \%+$ Dispersol as solvent. . & 4 & 51.5 & $\ddagger$ \\
\hline Paraffin oil only ............. & 4 & 57.0 & $\ddagger$ \\
\hline
\end{tabular}

* 0 , none; 1 , slight; 2 , moderate; 3 , abundant; 4 , dense.

$\dagger 0$, none; 1 , slight; 2 , moderate; 3 , abundant; 4 , complete.

$\ddagger$ Not possible to determine.

The following conclusions or impressions may be stated. The humectant propylene glycol did not assist in increasing the $\mathrm{MH}$ response in this test, nor was an improvement due to Methocel evident. The Carbowaxes were somewhat effective in promoting MH inhibition. All of the surfactants increased the inhibitory action of the MH. There was no apparent difference between 0.1, 0.2, and 0.5 per cent Vatsol OT. For Tween 20 and Tergitol $\mathrm{XC}$ dioleate, 0.1 per cent was slightly better than 1.0 per cent. For the other four nonionic surfactants, 1.0 per cent was superior to 0.1 per cent. Possibly some of the effects noted here are due to the humectant properties of the 
additives. Additional concentration series must be investigated before the significance of these tests can be assured.

Mixtures of $\mathrm{MH}$ and dalapon gave results that are difficult to explain. For both 1.0 per cent MH plus 1.0 per cent dalapon and 0.5 per cent plus 0.5 per cent amounts, no regrowth was observed 21 weeks after treatment. For 1.0 per cent MH plus 0.1 per cent dalapon there was moderate regrowth, indicating a possible antagonism. Kerosene (Dispersol) as a solvent was not successful, confirming earlier tests with oils. Paraffin oil sprayed on the

TABLE 5

\section{RESULTS OF OIL-CONTAINING MH FOLIAGE SPRAYS ON DUPLICATE CULTURES OF BERMUDAGRASS}

(Treatment date, December 20, 1953; data taken at harvest, 14 weeks later)

\begin{tabular}{|c|c|c|c|c|c|c|}
\hline \multirow{2}{*}{ Formulation } & \multicolumn{2}{|c|}{ Height in $\mathrm{cm}$} & \multicolumn{2}{|c|}{ Regrowth* } & \multicolumn{2}{|c|}{$\begin{array}{c}\text { Amount of } \\
\text { necrosist }\end{array}$} \\
\hline & A & B & A & B & & B \\
\hline 1. $100 \%$ Sovaspray . ........... & 33 & 36 & 4 & 4 & 0 & 0 \\
\hline 2. $100 \%$ Sovaspray; $0.05 \%$ Vatsol & 15 & 15 & 4 & 4 & 4 & 4 \\
\hline 3. $100 \%$ Sovaspray; $0.1 \%$ Vatsol. & 21 & 24 & 4 & 4 & 4 & 4 \\
\hline 4. $100 \%$ Sovaspray; $0.5 \%$ Vatsol. & 40 & 40 & 4 & 4 & 0 & 0 \\
\hline 5. $100 \%$ Sovaspray; $0.05 \%$ Vatsol; $1 \% \mathrm{MH}$. & 16 & 15 & 2 & 0 & 2 & 1 \\
\hline 6. $100 \%$ Sovaspray; $0.1 \%$ Vatsol; $1 \% \mathrm{MH}$. & 16 & 17 & 1 & 1 & 1 & 1 \\
\hline 7. $100 \%$ Sovaspray; $0.5 \%$ Vatsol; $1 \%$ MH... & 17 & 16 & 1 & 1 & 2 & 2 \\
\hline 8. $100 \%$ Multifilm WB........... & 42 & 50 & 4 & 4 & 0 & 0 \\
\hline 9. $50 \%$ Multifilm WB... & 33 & 42 & 4 & 4 & 0 & 0 \\
\hline 10. $10 \%$ Multifilm WB $\ldots$. & 43 & 44 & 4 & 4 & 0 & 0 \\
\hline 11. $1 \%$ Multifilm WB... & 30 & 39 & 4 & 4 & $\ddagger$ & 0 \\
\hline 12. $0.1 \%$ Multifilm WB......... & 36 & 43 & 4 & 4 & 0 & 0 \\
\hline 13. $100 \%$ Multifilm WB; $1 \%$ MH. & 38 & 42 & 4 & 4 & $\ddagger$ & 0 \\
\hline 14. $50 \%$ Multifilm WB; $1 \% \mathrm{MH}$. & 38 & 20 & 4 & 1 & $\ddagger$ & 3 \\
\hline 15. $10 \%$ Multifilm WB; $1 \% \mathrm{MH}$. & 18 & 17 & 0 & 0 & 3 & 3 \\
\hline 16. $1 \%$ Multifilm WB; $1 \% \mathrm{MH}$. & 16 & 25 & 0 & 0 & 1 & 1 \\
\hline 17. $0.1 \%$ Multifilm WB; $1 \%$ MH. & 21 & 25 & 1 & 1 & 3 & 4 \\
\hline 18. $100 \%$ Soltrol $\ldots \ldots \ldots \ldots \ldots \ldots$ & 36 & 48 & 4 & 4 & 0 & 0 \\
\hline 19. $100 \%$ Soltrol; $1 \%$ MH.. & 43 & 42 & 4 & 4 & 0 & 0 \\
\hline 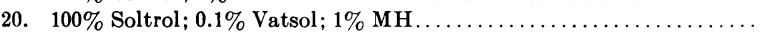 & 18 & 24 & 0 & 1 & 1 & 2 \\
\hline 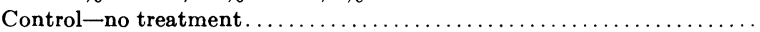 & 40 & 37 & 4 & 4 & 0 & 0 \\
\hline
\end{tabular}

*0, none; 1 , slight; 2 . moderate; 3 , abundant; 4 , dense.

t 0 , none; 1 , slight; 2 , moderate; 3 , abundant; 4 , complete.

$\ddagger$ Not possible to determine.

leaves after the MH-plus-Vatsol solution had dried seemed to be equal to, but no better than, the same spray minus the oil follow-up. As an effect of the oil spray, considerable leaf tissue was killed. Urea 0.5 per cent, borax 0.1 per cent, and ethanol 5.0 per cent, showed no promise. Endothal at 0.5 per cent surprisingly inhibited (antagonized) the MH effect.

Oil-Containing Formulations. Further tests on formulations utilized the nontoxic oils Sovaspray 100 and Soltrol and the surfactant preparations Multifilm WB and Vatsol OT. Bermudagrass plants were sprayed to run-off in the greenhouse. After 14 weeks the length of the shoots was measured, and the amounts of regrowth and acute injury to sprayed tissue were noted. Results are shown in table 5.

Regrowth was completely suppressed by only two of the treatments, having the following composition: No. 15, water as solvent, 10 per cent Multi- 
film WB, MH 1 per cent; No. 16, water as solvent, 1 per cent Multifilm WB, MH 1 per cent. An interesting result (Nos. 19 and 20) is that a surfactant added to oil as solvent increases effectiveness as it does in aqueous solutions. In conclusion, this experiment is further proof that oil carriers are not suitable for use with $\mathrm{MH}$.

From these observations it seems likely that MH traverses the surface layers of leaves via an aqueous rather than a lipoid route. Apparently this route is restricted because initial penetration is slow, requiring many hours for completion (Anon., 1956a, figs. 1 and 2). These data indicate why rainfall during the first. 24 hours following an MH spray treatment is detrimental to the treatment.

\section{After-Treatments}

Oil Sprays. Several years earlier Hoffman and Sylvester (1950) had found that mowing the tops of Polygonum species increased the effectiveness of $\mathrm{MH}$ to a marked degree. Having decided that the diethanolamine salt formulation was the most favorable of any available, we next tried aftertreatments to see if greater effectiveness might be achieved. The first series of tests used a variety of oils ranging from white medicinal oil of very low phytotoxicity to diesel fuel.

\section{TABLE 6}

REGROWTH OF BERMUDAGRASS AFTER MH (DEA) SPRAY AT 0.4 PER CENT ON OCTOBER 23, 1950, FOLLOWED BY AN OIL SPRAY ON OCTOBER 30, 1950

(Values represent average length of shoots)

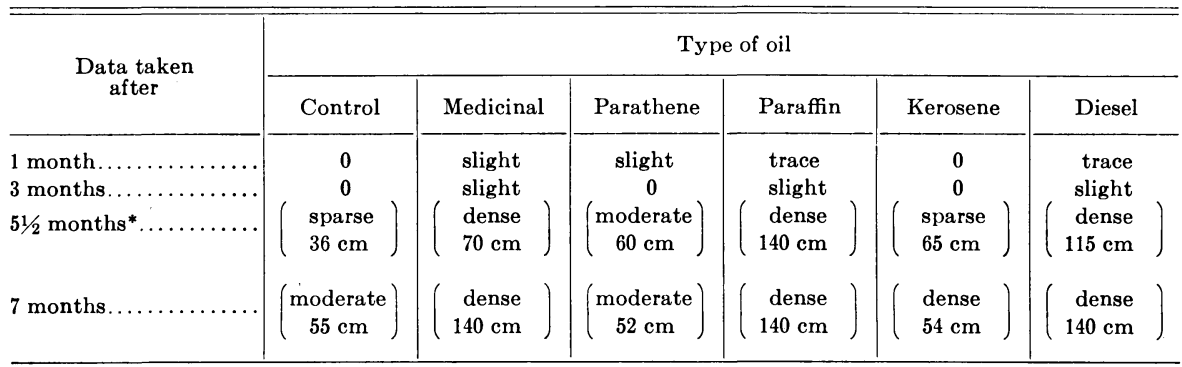

* Cultures clipped after these observations were made.

Table 6 presents the results of this test. From these data it is apparent that spraying with these oils after a 0.4 per cent $\mathrm{MH}$ spray had little effect on the toxicity; in fact, the medicinal oil, the paraffin oil, and the diesel fuel seemed to counteract the dormancy induced by the $\mathrm{MH}$.

Our next test involved MH sprays at $0.2,0.4$ and 0.6 per cent concentrations, followed in one week and in two weeks by sprays with Annalos No. 7 and Annalos No. 11. Annalos No. 7 is an Edleanu bottoms, a light, highly aromatic oil having a very high contact toxicity. It evaporates quite rapidly from the sprayed plants. Annalos No. 11 is a heavy, moderately aromatic bottoms obtained from the catalytic cracking of western crude oil in the manufacture of gasoline. It is considerably more persistent than Annalos No. 7. Annalos No. 11 is widely used as a general-contact weed oil; Annalos No. 7 is used as a weed oil and as a pre-harvest desiccant on alfalfa, clover, 
and grain sorghum. Table 7 gives the results of these tests. From these data it would appear that the toxic oils, particularly the heavy fraction, added considerably to the effectiveness of $\mathrm{MH}$ (fig. 4).

A repetition of the diesel oil follow-up spray was made, using $\mathrm{MH}$ at 0.4 per cent with 0.1 per cent Vatsol OT. The diesel oil sprays were applied on the seventh day after the MH sprays; straight diesel oil and diesel oil fortified with dinitro-secondary-butylphenol were used. The MH sprays

TABIE 7

REGROWTH OF BERMUDAGRASS CULTURES SPRAYED WITH MH ON DECEMBER 20, 1950, FOLLOWED IN ONE AND TWO WEEKS WITH OIL SPRAYS

\begin{tabular}{|c|c|c|c|c|c|c|}
\hline \multirow{3}{*}{ Date observed } & \multicolumn{2}{|c|}{ MH $0.2 \%$} & \multicolumn{2}{|c|}{ MH $0.4 \%$} & \multicolumn{2}{|c|}{ МH $0.6 \%$} \\
\hline & Annalog $\# 7$ & Annalos \# 11 & Annalos $\sharp 7$ & Annalos \#11 & Annalos $\# 7$ & Annalos \#11 \\
\hline & \multicolumn{6}{|c|}{ Oil sprays one week after MH sprays } \\
\hline $\begin{array}{l}1 / 22 / 51 \ldots \ldots \ldots \ldots \ldots \ldots \\
4 / 5 / 51 \ldots \ldots \ldots \ldots \ldots \ldots \ldots \\
7 / 26 / 51 \ldots \ldots \ldots \ldots \ldots \ldots \\
10 / 8 / 51 \ldots \ldots \ldots \ldots \ldots \ldots \ldots\end{array}$ & \begin{tabular}{l}
\multicolumn{1}{c}{0} \\
Mod. \\
Dense \\
Dense
\end{tabular} & $\begin{array}{l}\quad 0 \\
\text { Slight } \\
\text { Mod. } \\
\text { Dense }\end{array}$ & $\begin{array}{l}\quad 0 \\
\text { Mod. } \\
\text { Dense } \\
\text { Dead }\end{array}$ & $\begin{array}{l}0 \\
0 \\
0 \\
0\end{array}$ & $\begin{array}{l}0 \\
0 \\
0 \\
0\end{array}$ & $\begin{array}{l}0 \\
0 \\
0 \\
0\end{array}$ \\
\hline $10 / 8 / 51 \ldots \ldots \ldots \ldots \ldots$ & \multicolumn{6}{|c|}{ Oil sprays two weeks after $\mathrm{MH}$ sprays } \\
\hline $\begin{array}{l}1 / 22 / 51 \ldots \ldots \ldots \ldots \ldots \ldots \\
4 / 5 / 51 \ldots \ldots \ldots \ldots \ldots \ldots \ldots \\
7 / 26 / 51 \ldots \ldots \ldots \ldots \ldots \ldots \\
10 / 8 / 51 \ldots \ldots \ldots \ldots \ldots \ldots\end{array}$ & $\begin{array}{l}\quad 0 \\
\text { Mod. } \\
\text { Dense } \\
\text { Dense }\end{array}$ & $\begin{array}{l}\quad 0 \\
\text { Mod. } \\
\text { Dense } \\
\text { Dense }\end{array}$ & $\begin{array}{l}\text { 0 } \\
\text { Mod. } \\
\text { Dense } \\
\text { Dense }\end{array}$ & $\begin{array}{l}0 \\
0 \\
0 \\
0\end{array}$ & $\begin{array}{l}\quad 0 \\
\text { Mod. } \\
\text { Mod. } \\
\text { Mod. }\end{array}$ & $\begin{array}{l}0 \\
0 \\
0 \\
0\end{array}$ \\
\hline
\end{tabular}

were applied October 2, 1950, and the experiment was ended July 26, 1951. All cultures had moderate-to-dense regrowth. Apparently 0.4 per cent concentration was not enough to give complete killing by this method.

Oils, Trichloroacetic Acid (TCA), Sodium Chlorate $\left(\mathrm{NaClO}_{3}\right)$, and 2,4-D. A final test, using 0.4 per cent MH with Vatsol OT at 0.5 per cent as a wetting agent, explored eight follow-up sprays; three of these were oils, five were aqueous (TCA, Ammate, and repeat sprays with $\mathrm{MH}, \mathrm{NaClO}_{3}$, and 2,4-D). The aqueous sprays all contained Multifilm L at 0.05 per cent concentration as a penetrant. Each treatment was applied to three cultures: young, recently potted plants; old, vigorous established plants; and established plants clipped to 3 inches just before treatment. Table 8 presents the data on this experiment. Apparently the sodium chlorate spray added to the effectiveness of MH ; repeated spraying with MH helped some; possibly TCA added somewhat.

Clipping. A test on the effects of clipping Bermudagrass at various intervals after spraying proved that removal of tops after two and four days completely eliminated the effects of $\mathrm{MH}$ spray ( 0.4 per cent $\mathrm{MH}$ plus 0.1 per cent Vatsol OT). With an eight-day interval top growth was inhibited for three months, but the plants recovered in five months. When the interval was 16 days, there was still inhibition five months after spraying, but the plants were recovering. This experiment indicates that the absorption of 
MH by Bermudagrass under the low-humidity conditions of the greenhouse used was relatively slow. This is in agreement with the studies of Zukel et al. (1956) of the Naugatuck Chemical Division.

Repeated MH Application. As shown in table 8, spraying with $\mathrm{MH}$, followed in two weeks with a second $\mathrm{MH}$ application, gave promising results. A more detailed report on repeated $\mathrm{MH}$ spraying is given in table 9. The

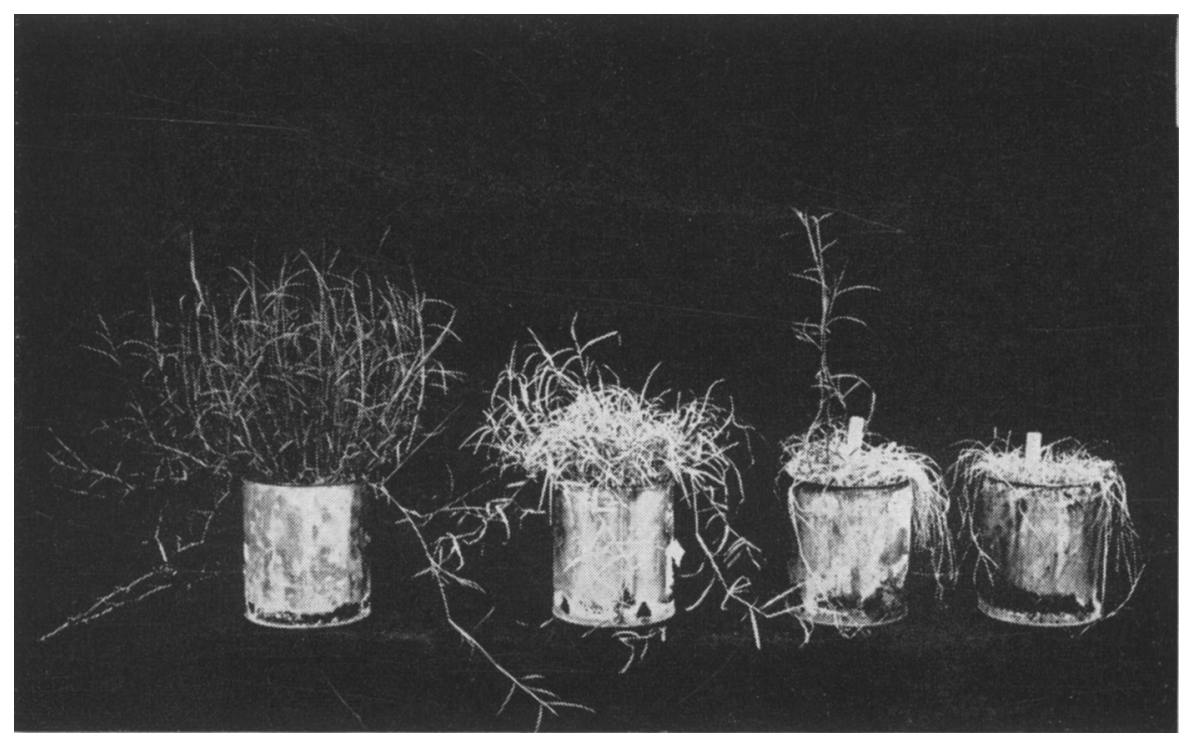

Fig. 4. Bermudagrass cultures, showing the effect of $\mathrm{MH}$ followed by oil sprays. Left to right: untreated control; $\mathrm{MH}, 0.6$ per cent; $\mathrm{MH}, 0.6$ per cent, followed by Annalos No. 7 ; MH, 0.6 per cent, followed by Annalos No. 11. MH sprays applied Dee. 20, 1950, oil sprays Jan. 3, 1951. Photograph taken March 15, 1951.

plants were well-established Bermudagrass cultures. The MH solutions contained $0.1,0.2,0.3$ and 0.4 per cent $\mathrm{MH}$ respectively, and all had 0.1 per cent Vatsol OT. One set of plants received three applications and a second set was sprayed seven times. Dates of spraying and observation are given in the table.

Seven applications apparently had little if any advantage over three. It should be noted that all cultures in the set receiving three applications were active at the time of the third application on December 20, 1950. On the other hand, only the cultures sprayed with the 0.1 per cent $\mathrm{MH}$ were active after six applications. Evidently the repeated spraying on dormant plants had little or no physiological effect, with the possible exception of the 0.4 per cent application. Apparently the physiological state of the plant is very important with regard to response to $\mathrm{MH}$.

\section{Effect of Plant Condition}

Age of Plants. To further explore the influence of various conditions of plant growth on the effectiveness of MH sprays, on June 23, 1952, sprays were applied to groups of Bermudagrass plants established in the greenhouse for 7 days, 53 days, and 6 months. The MH sprays contained 0.5, 1.0, 2.0, 


\section{TABLE 8}

REGROWTH OF TRIPLICATE BERMUDAGRASS CULTURES SPRAYED WITH MH AT 0.4 PER CENT PLUS VATSOL OT 0.5 PER CENT ON MAY 4, 1951,

AND SPRAYEIU MLAY 18 WITH OTHER TOXICANTS*

(Values represent average length of shoots)

\begin{tabular}{|c|c|c|c|c|c|c|}
\hline \multirow{2}{*}{ Treatment } & & \multicolumn{5}{|c|}{ Date of observation } \\
\hline & & May 22 & May 28 & July 13 & Oct. 8 & Jan. 18 \\
\hline Control-untreated & $\begin{array}{l}\text { A } \\
\text { B } \\
\text { C }\end{array}$ & $\begin{array}{l}+22 \mathrm{~cm} \\
+28 \mathrm{~cm} \\
+30 \mathrm{~cm}\end{array}$ & $\begin{array}{l}+24 \mathrm{~cm} \\
+30 \mathrm{~cm} \\
+31 \mathrm{~cm}\end{array}$ & $\begin{array}{l}+20 \mathrm{~cm} \\
+60 \mathrm{~cm} \\
+70 \mathrm{~cm}\end{array}$ & $\begin{array}{l}\text { + Dense } \\
+ \text { Dense } \\
+ \text { Dense }\end{array}$ & $\begin{array}{l}\text { Dense } \\
\text { Dense } \\
\text { Dense }\end{array}$ \\
\hline Control-MH + Vatsol & $\begin{array}{l}\text { A } \\
\text { B } \\
\text { C }\end{array}$ & $\begin{array}{l}+18 \mathrm{~cm} \\
+28 \mathrm{~cm} \\
+18 \mathrm{~cm}\end{array}$ & $\begin{array}{l}+18 \mathrm{~cm} \\
+28 \mathrm{~cm} \\
+18 \mathrm{~cm}\end{array}$ & $\begin{array}{l}0 \\
0 \\
0\end{array}$ & $\begin{array}{l}\text { Mod. } 50 \mathrm{~cm} \\
\text { Mod. } 70 \mathrm{~cm} \\
\text { Mod. } 44 \mathrm{~cm}\end{array}$ & $\begin{array}{l}\text { Mod. } 35 \mathrm{~cm} \\
\text { Dense } 35 \mathrm{~cm} \\
\text { Mod. } 38 \mathrm{~cm}\end{array}$ \\
\hline MH spray + TCA $1 / 2 \mathrm{lb} /$ gal & $\begin{array}{l}\text { A } \\
\text { B } \\
\text { C }\end{array}$ & $\begin{array}{l}0 \\
0 \\
0\end{array}$ & $\begin{array}{l}0 \\
0 \\
0\end{array}$ & $\begin{array}{l}0 \\
0 \\
0\end{array}$ & $\begin{array}{c}\text { Sl. } 20 \mathrm{~cm} \\
0 \\
0\end{array}$ & $\begin{array}{c}\text { Sl. } 32 \mathrm{~cm} \\
0 \\
\text { Mod. } 48 \mathrm{~cm}\end{array}$ \\
\hline MH spray + Annalos $\# 7$ & $\begin{array}{l}\text { A } \\
\text { B } \\
\text { C }\end{array}$ & $\begin{array}{l}0 \\
0 \\
0\end{array}$ & $\begin{array}{l}0 \\
0 \\
0\end{array}$ & $\begin{array}{l}+4 \mathrm{~cm} \\
+15 \mathrm{~cm} \\
+10 \mathrm{~cm}\end{array}$ & $\begin{array}{r}+68 \mathrm{~cm} \\
+90 \mathrm{~cm} \\
+100 \mathrm{~cm}\end{array}$ & $\begin{array}{l}\text { Mod. } 15 \mathrm{~cm} \\
\text { Mod. } 20 \mathrm{~cm} \\
\text { Mod. } 25 \mathrm{~cm}\end{array}$ \\
\hline MH spray + Annalos \#11 & $\begin{array}{l}\text { A } \\
\text { B } \\
\text { C }\end{array}$ & $\begin{array}{l}0 \\
0 \\
0\end{array}$ & $\begin{array}{l}0 \\
0 \\
0\end{array}$ & $\begin{array}{c}+11 \mathrm{~cm} \\
+8 \mathrm{~cm} \\
0\end{array}$ & $\begin{array}{r}+ \\
+ \\
0\end{array}$ & $\begin{array}{c}\text { Dense } 20 \mathrm{~cm} \\
\text { Mod. } 25 \mathrm{~cm} \\
0\end{array}$ \\
\hline MH spray + Diesel oil & $\begin{array}{l}\text { A } \\
\text { B } \\
\text { C }\end{array}$ & $\begin{array}{l}0 \\
0 \\
0\end{array}$ & $\begin{array}{l}0 \\
0 \\
0\end{array}$ & $\begin{array}{c}+6 \mathrm{~cm} \\
0 \\
0\end{array}$ & $\begin{array}{c}+65 \mathrm{~cm} \\
+50 \mathrm{~cm} \\
0\end{array}$ & $\begin{array}{l}\text { Mod. } 35 \mathrm{~cm} \\
\text { Mod. } 38 \mathrm{~cm} \\
\text { Mod. } 20 \mathrm{~cm}\end{array}$ \\
\hline MH spray + ammate $1 \mathrm{lb} / \mathrm{gal}$ & $\begin{array}{l}\text { A } \\
\text { B } \\
\text { C }\end{array}$ & $\begin{array}{l}0 \\
0 \\
0\end{array}$ & $\begin{array}{l}0 \\
0 \\
0\end{array}$ & $\begin{array}{l}0 \\
0 \\
0\end{array}$ & $\begin{array}{r}+37 \mathrm{~cm} \\
+45 \mathrm{~cm} \\
+105 \mathrm{~cm}\end{array}$ & $\begin{array}{l}\text { Mod. } 15 \mathrm{~cm} \\
\text { Mod. } 20 \mathrm{~cm} \\
\text { Mod. } 25 \mathrm{~cm}\end{array}$ \\
\hline MH spray + MH spray & $\begin{array}{l}\text { A } \\
\text { B } \\
\text { C }\end{array}$ & $\begin{array}{l}+ \\
+ \\
+\end{array}$ & $\begin{array}{l}+ \\
+ \\
+\end{array}$ & $\begin{array}{l}0 \\
0 \\
0\end{array}$ & $\begin{array}{l}0 \\
0 \\
0\end{array}$ & $\begin{array}{l}\text { Mod. } 25 \mathrm{~cm} \\
\text { Sl. } 12 \mathrm{~cm} \\
0\end{array}$ \\
\hline $\mathrm{MH}$ spray $+\mathrm{NaClO}_{3} 1 \mathrm{lb} / \mathrm{gal}$ & $\begin{array}{l}\text { A } \\
\text { B } \\
\text { C }\end{array}$ & $\begin{array}{l}0 \\
0 \\
0\end{array}$ & $\begin{array}{l}0 \\
0 \\
0\end{array}$ & $\begin{array}{l}0 \\
0 \\
0\end{array}$ & $\begin{array}{l}0 \\
0 \\
0\end{array}$ & $\begin{array}{c}0 \\
\text { Dense } 35 \mathrm{~cm} \\
0\end{array}$ \\
\hline MH spray $+2,4-\mathrm{D} 0.2 \%$ & $\begin{array}{l}\text { A } \\
\text { B } \\
\text { C }\end{array}$ & $\begin{array}{l}+20 \mathrm{~cm} \\
+22 \mathrm{~cm} \\
+20 \mathrm{~cm}\end{array}$ & $\begin{array}{l}+20 \mathrm{~cm} \\
+22 \mathrm{~cm} \\
+20 \mathrm{~cm}\end{array}$ & $\begin{array}{l}+ \\
+ \\
+\end{array}$ & $\begin{array}{l}+20 \mathrm{~cm} \\
+32 \mathrm{~cm} \\
+62 \mathrm{~cm}\end{array}$ & $\begin{array}{l}\text { Dense } \\
\text { Dense } \\
\text { Dense }\end{array}$ \\
\hline
\end{tabular}

$0=$ no growth, $+=$ some growth, mod. $=$ moderate, sl. $=$ slight.
${ }^{*}$ All cultures were clipped to 3 inches on July 13 and October 8.

and 4.0 per cent $\mathrm{MH}$ as the diethanolamine salt, each with 0.1 per cent Vatsol OT. At harvest, on October 30, 1952, the regrowth of cultures sprayed with $\mathrm{MH}$ at 0.5 per cent concentration weighed $38.4,21.5$, and $11.6 \mathrm{gm}$ for the 7-day, 53-day, and 6-month cultures respectively. Regrowth produced by the 7 -day cultures weighed $38.2,38.9$, and $34.7 \mathrm{gm}$ for the 1.0, 2.0, and 4.0 per cent concentrations respectively. The 53-day and 6 month cultures produced no regrowth and were recorded at $0 \mathrm{gm}$ of active shoot tissue. 
A similar experiment was performed in July, 1952. At the fourth harvest in June, 1953, plants sprayed when they had been established for 21 days had active growth throughout the range of concentrations of MH $(0,1.0$, 2.0 , and 4.0 per cent). Plants sprayed at 65 days and at 6 months had less regrowth at 1.0 and 2.0 per cent concentrations and none at 4.0 per cent. From these two tests it is evident that the growing condition of the Bermudagrass cultures is an important factor in experiments with MH and that plants established less than two months do not respond in the same way as older, more stable cultures. Since field infestations of this grass

TABLE 9

RESPROUTING AND HEIGHT OF REGROWTH OF TWO SPRAY SERIES OF BERMUDAGRASS CULTURES

(Values are length of longest shoots)

\begin{tabular}{|c|c|c|c|c|c|c|c|}
\hline \multirow{2}{*}{ Treatment } & \multirow{2}{*}{$\begin{array}{c}\mathrm{MH} \\
\text { concen- } \\
\text { tration }\end{array}$} & \multicolumn{6}{|c|}{ Date of observation } \\
\hline & & $12 / 20 / 50$ & $4 / 4 / 51$ & $5 / 28 / 51^{*}$ & $7 / 26 / 51^{*}$ & $10 / 8 / 51^{*}$ & $1 / 18 / 52 \dagger$ \\
\hline $\begin{array}{l}\text { Sprayed three times: } \\
10 / 31 / 49,11 / 15 / 49 \\
12 / 20 / 50\end{array}$ & $\begin{array}{l}0.1 \% \\
0.2 \% \\
0.3 \% \\
0.4 \%\end{array}$ & $\begin{array}{c}+ \\
+ \\
+ \\
+15 \mathrm{~cm}\end{array}$ & $\begin{array}{c}+64 \mathrm{~cm} \\
+42 \mathrm{~cm} \\
0 \\
0\end{array}$ & $\begin{array}{c}+75 \mathrm{~cm} \\
+70 \mathrm{~cm} \\
+50 \mathrm{~cm} \\
0\end{array}$ & $\begin{array}{c}+55 \mathrm{~cm} \\
+60 \mathrm{~cm} \\
+80 \mathrm{~cm} \\
0\end{array}$ & $\begin{array}{c}+38 \mathrm{~cm} \\
+42 \mathrm{~cm} \\
+50 \mathrm{~cm} \\
0\end{array}$ & $\begin{array}{c}\text { Av. } 35 \mathrm{~cm} \\
\text { Av. } 25 \mathrm{~cm} \\
\text { Av. } 25 \mathrm{~cm} \\
0\end{array}$ \\
\hline $\begin{array}{c}\text { Sprayed seven times: } \\
10 / 31 / 49,11 / 15 / 49 \\
11 / 29 / 49,12 / 12 / 49 \\
12 / 30 / 49,1 / 20 / 50 \\
12 / 20 / 50\end{array}$ & $\begin{array}{l}0.1 \% \\
0.2 \% \\
0.3 \% \\
0.4 \%\end{array}$ & $\begin{array}{c}+ \\
0 \\
0 \\
\text { Slight }\end{array}$ & $\begin{array}{c}+72 \mathrm{~cm} \\
+42 \mathrm{~cm} \\
+50 \mathrm{~cm} \\
0\end{array}$ & $\begin{array}{c}+85 \mathrm{~cm} \\
+70 \mathrm{~cm} \\
+75 \mathrm{~cm} \\
0\end{array}$ & $\begin{array}{c}+57 \mathrm{~cm} \\
+110 \mathrm{~cm} \\
+110 \mathrm{~cm} \\
0\end{array}$ & $\begin{array}{c}+50 \mathrm{~cm} \\
+135 \mathrm{~cm} \\
+125 \mathrm{~cm} \\
0\end{array}$ & $\begin{array}{c}\text { Av. } 25 \mathrm{~cm} \\
\text { Av. } 30 \mathrm{~cm} \\
\text { Av. } 80 \mathrm{~cm} \\
0\end{array}$ \\
\hline
\end{tabular}

$0=$ no growth, $+=$ some growth.

* Cultures clipped short following observation.

$\dagger$ Av. = average length of all shoots.

are usually several years old, experimental work that is related to field practice should use old, well-established cultures. This was considered in subsequent tests.

Subdivision of Rhizomes. From tables 7 and 9 it is evident that increasing the amount of MH used per culture increases the effectiveness. Since it was thought that breaking up the rhizomes of MH-treated Bermudagrass might further the injury, and a rapid-killing action was sought, a group of eultures was sprayed with a 4.0 per cent solution of the diethanolamine salt formulation (MH-30) plus 0.1 per cent Vatsol OT. After intervals of $1,4,8$, and 16 days, duplicate cultures were removed from the cans, the tops were cut into 3 -inch lengths, the rhizomes into 1 -inch lengths, and the crowns with some surrounding soil were separated. The cut tops were returned to the bottoms of the eans. The cut rhizomes were mixed with the soil and returned to the can. The crowns were separated and placed an inch below the soil surface. The cultures were watered and tended as usual. Four control cultures were kept for each of the interval treatments listed. Two of these were harvested on September 19, 1952, two on October 29, 1952. The treated cultures were examined and measured, and the soil was repulverized on October 29, 1952, February 9, 1953, April 28, 1953, and August 20, 1953. The data are presented in table 10. 
Three deductions seem evident from these data; first, the high dosage of $\mathrm{MH}$ used was much more effective than those previously used (see fig. 5); second, simulated tillage had a profound effect in killing the treated plants; and third, the one-day interval between spraying and tillage was too short for adequate distribution of the chemical throughout the plant.

Simulated Tillage Plus Fertilizer. In a second experiment concentrations of MH (as DEA salt) of 1.0, 2.0, and 4.0 per cent, all with 0.1 per cent Vatsol OT, were used in conjunction with simulated tillage at intervals of $2,4,8$,

TABLE 10

EFFECTS OF MH PLUS TILLAGE ON REGROWTH OF BERMUDAGRASS CULTURES TREATED JUNE 23, 1952

\begin{tabular}{|c|c|c|c|c|c|c|c|}
\hline \multirow{2}{*}{$\begin{array}{l}\text { Interval } \\
\text { between } \\
\text { spraying and } \\
\text { tillage }\end{array}$} & \multirow{2}{*}{$\begin{array}{c}\text { Description of } \\
\text { regrowth }\end{array}$} & \multicolumn{2}{|c|}{ Controls } & \multicolumn{4}{|c|}{ Treated cultures } \\
\hline & & $9 / 19 / 52$ & $10 / 29 / 52$ & $10 / 29 / 52$ & $2 / 9 / 53$ & $4 / 28 / 53$ & $8 / 20 / 53$ \\
\hline 1 day & 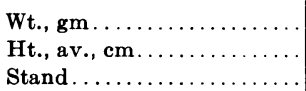 & $\begin{array}{c}34.9 \\
60 \\
\text { Dense }\end{array}$ & $\begin{array}{c}16.9 \\
40 \\
\text { Mod. }\end{array}$ & $\begin{array}{l}1.2 \\
36 \\
\text { Sl. }\end{array}$ & $\begin{array}{l}1.4 \\
45 \\
\text { Sl. }\end{array}$ & $\begin{array}{l}8.5 \\
32 \\
\text { Sl. }\end{array}$ & $\begin{array}{l}8.0 \\
20 \\
\text { Sl. }\end{array}$ \\
\hline 4 days & 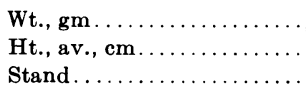 & $\begin{array}{l}32.1 \\
60 \\
\text { Mod. }\end{array}$ & $\begin{array}{l}13.0 \\
47 \\
\text { Mod. }\end{array}$ & $\begin{array}{l}0 \\
0 \\
0\end{array}$ & $\begin{array}{l}0 \\
0 \\
0\end{array}$ & $\begin{array}{l}0 \\
0 \\
0\end{array}$ & $\begin{array}{l}0 \\
0 \\
0\end{array}$ \\
\hline 8 days & $\begin{array}{l}\text { Wt., gm.............. } \\
\text { Ht., av., cm.......... } \\
\text { Stand............... }\end{array}$ & $\begin{array}{l}21.1 \\
55 \\
\text { Mod. }\end{array}$ & $\begin{array}{l}10.7 \\
40 \\
\text { Light }\end{array}$ & $\begin{array}{l}0 \\
0 \\
0\end{array}$ & $\begin{array}{l}0 \\
0 \\
0\end{array}$ & $\begin{array}{l}0 \\
0 \\
0\end{array}$ & $\begin{array}{l}0 \\
0 \\
0\end{array}$ \\
\hline 16 days & 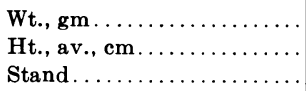 & $\begin{array}{c}31.9 \\
52 \\
\text { Dense }\end{array}$ & $\begin{array}{l}19.1 \\
46 \\
\text { Mod. }\end{array}$ & $\begin{array}{l}0 \\
0 \\
0\end{array}$ & $\begin{array}{l}0 \\
0 \\
0\end{array}$ & $\begin{array}{l}0 \\
0 \\
0\end{array}$ & $\begin{array}{l}0 \\
0 \\
0\end{array}$ \\
\hline
\end{tabular}

and 16 days after the spray application. One pair of cultures with the 2.0 per cent $\mathrm{MH}$ dosage was treated with 200 ec of 2.5 per cent $\left(\mathrm{NH}_{4}\right)_{2} \mathrm{SO}_{4}$ solution just after tillage. In this test the tillage operation conducted 4 days after spraying was considerably more effective than the $2-, 8$-, and 16 -day intervals. Again, tillage consisted of subdividing the top growth into 3-inch lengths and the rhizomes into 1-inch lengths, and separating the crowns. All pieces were mixed with the soil and replaced in cans in such a way that nothing showed above the soil surface. The addition of $\left(\mathrm{NH}_{4}\right)_{2} \mathrm{SO}_{4}$ did not seem to increase the effectiveness of the treatment. In the 2.0 and 4.0 per cent $\mathrm{MH}$ treatments there was no regrowth 176 days after the initial spray treatment.

This experiment was repeated, the initial spraying being performed on June 30, 1953. The ammonium sulphate supplement was used on one set of 2.0 per cent $\mathrm{MH}$ treatments with the hope that it might promote bacterial decay of the plant parts buried in the soil mass.

In this experiment all cultures were duplicated. Because no regrowth had occurred, except in one culture, on August 24, 1953, one culture of each pair (B) was removed and the top cut off; the rhizomes were examined, replanted, and covered with an inch of soil. Again, on December 23, 1953, the $\mathrm{B}$ cultures were removed, weighed, and replanted. The A cultures were not disturbed. The date of final harvest was May 6, 1954. This time all cultures were weighed. Results of the weighings are presented in table 11. 
Probably most notable is the fact that disturbing the cultures two months after the initial treatment had a definite deleterious effect on the herbicidal action, as indicated by the amount of regrowth. The B cultures were noticeably more active than those that remained undisturbed. Again, the ammonium sulfate seemed to have no effect on decomposition of the rhizomes. And again the 8-and 16-day intervals between spraying and the simulated tillage were detrimental to the killing effects of the MH.

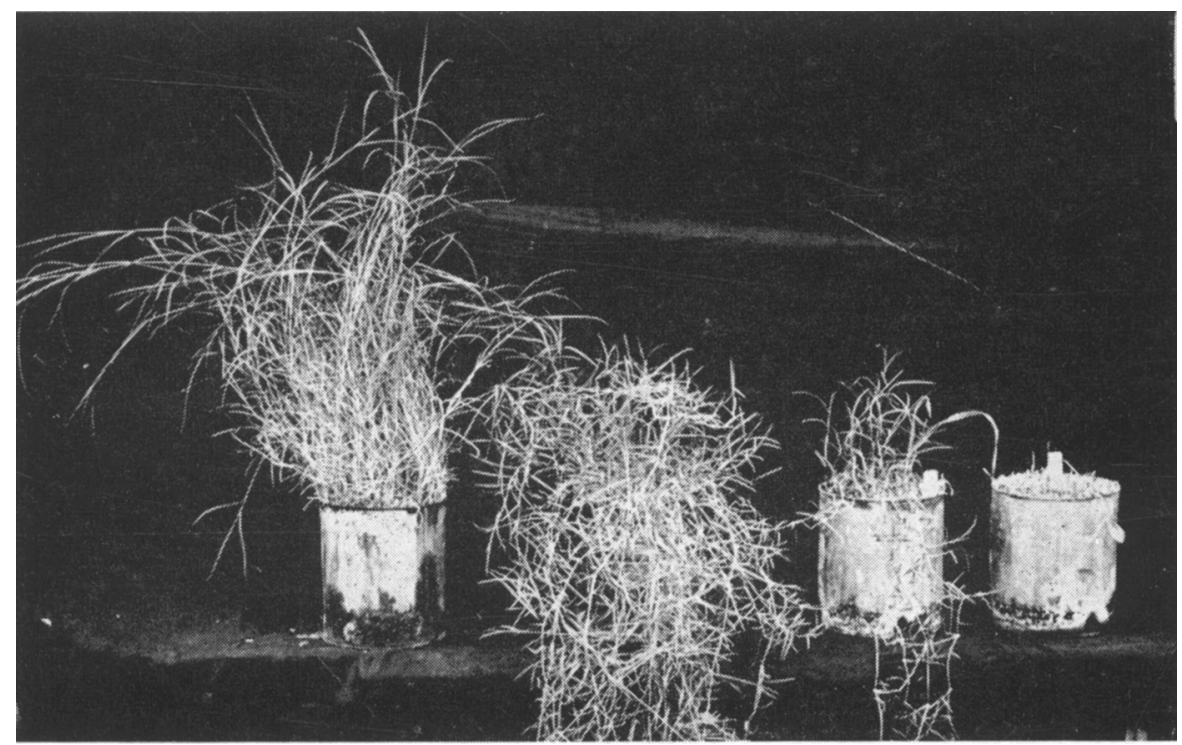

Fig. 5. Dosage series with $\mathrm{MH}$ sprays on Bermudagrass. Left to right: untreated control; $\mathrm{MH}, 0.4$ per cent; $\mathrm{MH}, 0.8$ per cent; $\mathrm{MH}, 1.6$ per cent. Cultures sprayed July 6 , 1950, photographed April 4, 1951. The two right-hand cultures are the ones shown in figure 1, and they emphasize the fact that the soil carried no $\mathrm{MH}$ residue.

Maturity of Foliage. The experiments described above seemed to establish that an MH concentration of at least 2.0 per cent with 0.1 per cent Vatsol OT as a wetting agent is a desirable spray treatment against Bermudagrass, and that tillage on the fourth day after spraying greatly increases the effectiveness. Stage of growth at spraying time was not considered. In order to explore the possible effects of varying maturity of foliage, 100 cultures of Bermudagrass were selected and prepared for the test. Five lots of 20 cultures each were matched, and the foliage was clipped to an average length between 2 and 3 inches on June 15, 1954. The cultures were sprayed according to the following schedule: the first lot was sprayed on June 29, 14 days after clipping; the second lot was sprayed 21 days after clipping; the third, 27 days; the fourth, 34 days ; and the fifth, 41 days. Average heights of foliage at spraying time were: 14 days, $21.3 \mathrm{~cm}$; 21 days, $24.2 \mathrm{~cm} ; 27$ days, $51.8 \mathrm{~cm}$; 34 days, $57.2 \mathrm{~cm} ; 41$ days, $51.0 \mathrm{~cm}$. The spray formulation contained 2.0 per cent $\mathrm{MH}$ as the diethanolamine salt plus 0.1 per cent Vatsol OT. Four days after the spray application each lot of cultures was given the simulated tillage treatment. In each group four cultures served as untreated clipped controls, 
four as ammonium sulfate-treated controls, four received MH only, four MH plus ammonium sulfate equivalent to 20 pounds per 1,000 square feet, and four MH plus 40 pounds ammonium sulfate per 1,000 square feet.

Table 12 presents the results of this test. From the data it seems that 14 days' growth after clipping was sufficient for the cultures to absorb an effective amount of MH so that they were still dormant more than nine months after the original clipping. As longer and longer intervals elapsed

TABLE 11

WEIGHT OF REGROWTH AND LIVING DORMANT RHIZOMES FROM DUPLICATE MH-TREATED BERMUDAGRASS CULTURES.

SPRAYING DATE JUNE 30, 1953

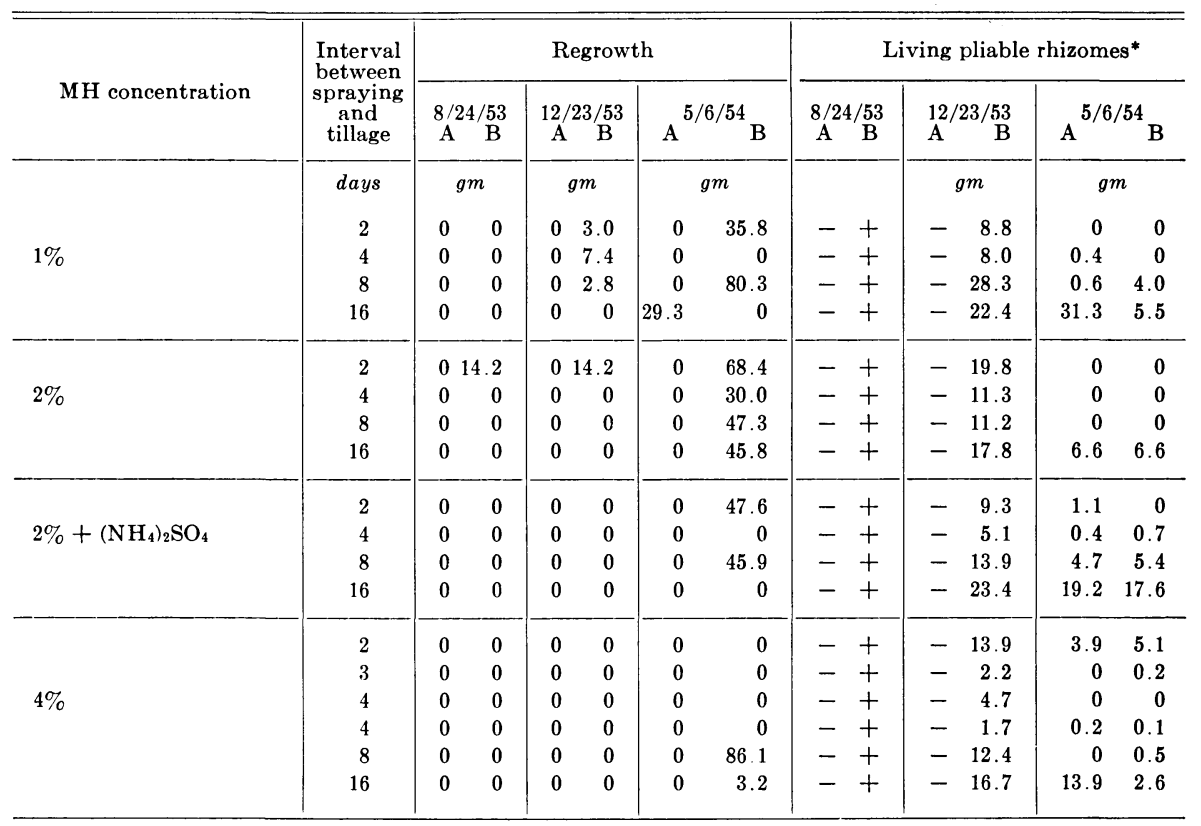

$-=$ no data taken, $+=$ living.

* Pliability indicates viable condition.

between clipping and spraying, more regrowth occurred. Again, in this test the application of ammonium sulfate had no significant effect in hastening decay of the buried rhizomes.

Our next experiment involved combinations of simulated tillage, $\mathrm{MH}$ spraying, and fertilization with ammonium sulfate and phosphoric acid. The fertilizers were applied at rates equivalent to 40 pounds of ammonium sulfate per 1,000 square feet and 70 pounds of phosphate on a like area.

Table 13 gives the treatment schedule and harvest data. The Bermudagrass cultures were well established, having been transplanted from the field into the can cultures in late 1953 and clipped occasionally to maintain a vegetative state. Stems were about $50 \mathrm{~cm}$ long at the time of treatment. The MH spray was 2.0 per cent in concentration with 0.1 per cent Vatsol OT. There were four replicates of each treatment. 
Several conclusions are evident from these data. Of the first five control cultures, which did not receive $\mathrm{MH}$, the nitrogen added, either before turning or after, stimulated growth so that in the three-month interim top growth was vigorous and all plant material was in an active state. Phosphate had no such effect on these cultures. In fact, phosphate added after turning

TABLE 12

WEIGHT OF SHOOT REGROWTH AND VIABLE: RHIZOMES FROM

BERMUDAGRASS CULTURES CLIPPED JUNE 15, 1954, AND

AFTERWARDS SPRAYED WITH MH AT VARIOUS

STAGES OF GROWTH

(Values are the totals of four replicates)

\begin{tabular}{|c|c|c|c|c|c|c|}
\hline \multirow{2}{*}{\multicolumn{2}{|c|}{$\begin{array}{c}\text { Treatment and dates } \\
\text { of observation }\end{array}$}} & \multicolumn{5}{|c|}{ Interval between clipping and spraying } \\
\hline & & 14 days & 21 days & 27 days & 34 days & 41 days \\
\hline \multirow{2}{*}{$\begin{array}{r}\text { Control: } \\
1 / 15 / 55\end{array}$} & & $g m$ & $g m$ & $g m$ & $g m$ & $g m$ \\
\hline & 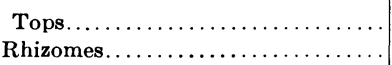 & $\begin{array}{r}29.0 \\
0.0\end{array}$ & $\begin{array}{r}25.0 \\
0.0\end{array}$ & $\begin{array}{r}47.4 \\
0.0\end{array}$ & $\begin{array}{r}48.7 \\
0.0\end{array}$ & $\begin{array}{r}147.6 \\
0.0\end{array}$ \\
\hline $3 / 28 / 55^{*}$ & $\begin{array}{l}\text { Tops } \ldots \ldots \ldots \ldots \ldots \ldots \ldots \ldots \\
\text { Rhizomes } \ldots \ldots \ldots \ldots \ldots \ldots \ldots\end{array}$ & $\begin{array}{l}\cdots \\
\cdots\end{array}$ & $\begin{array}{l}\cdots \\
\cdots\end{array}$ & $\begin{array}{l}\cdots \\
\cdots\end{array}$ & $\begin{array}{l}\cdots \\
\cdots\end{array}$ & $\begin{array}{l}\cdots \\
\cdots\end{array}$ \\
\hline \multicolumn{2}{|c|}{$\left(\mathrm{NH}_{4}\right)_{2} \mathrm{SO}_{4}$ control: } & & & & & \\
\hline $1 / 15 / 55$ & $\begin{array}{l}\text { Tops............... } \\
\text { Rhizomes....... }\end{array}$ & $\begin{array}{r}51.4 \\
0.0\end{array}$ & $\begin{array}{r}130.6 \\
0.0\end{array}$ & $\begin{array}{r}106.3 \\
0.0\end{array}$ & $\begin{array}{r}94.4 \\
0.0\end{array}$ & $\begin{array}{r}168.4 \\
0.0\end{array}$ \\
\hline $3 / 28 / 55^{*}$ & $\begin{array}{l}\text { Tops............. } \\
\text { Rhizomes...... }\end{array}$ & $\begin{array}{l}\cdots \\
\cdots\end{array}$ & $\begin{array}{l}\cdots \\
\cdots\end{array}$ & $\begin{array}{l}\cdots \\
\cdots\end{array}$ & $\begin{array}{l}\cdots \\
\cdots\end{array}$ & $\begin{array}{l}\cdots \\
\cdots\end{array}$ \\
\hline \multicolumn{2}{|l|}{ MH spray: } & & & & & \\
\hline $1 / 15 / 55$ & 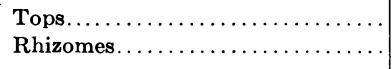 & $\begin{array}{l}0.0 \\
0.0\end{array}$ & $\begin{array}{l}2.3 \\
0.2\end{array}$ & $\begin{array}{l}4.2 \\
0.6\end{array}$ & $\begin{array}{l}3.4 \\
0.2\end{array}$ & $\begin{array}{l}5.8 \\
2.8\end{array}$ \\
\hline $3 / 28 / 55$ & $\begin{array}{l}\text { Tops } \ldots \ldots \ldots \ldots \ldots \ldots \\
\text { Rhizomes... }\end{array}$ & $\begin{array}{l}0.0 \\
0.0\end{array}$ & $\begin{array}{l}0.0 \\
0.0\end{array}$ & $\begin{array}{l}0.0 \\
0.4\end{array}$ & $\begin{array}{l}0.0 \\
1.9\end{array}$ & $\begin{array}{l}4.0 \\
4.6\end{array}$ \\
\hline \multicolumn{2}{|c|}{ MH plus 20 lbs. $\left(\mathrm{NH}_{4}\right)_{2} \mathrm{SO}_{4}$ : } & & & & & \\
\hline $1 / 15 / 55$ & $\begin{array}{l}\text { Tops..................... } \\
\text { Rhizomes........ }\end{array}$ & $\begin{array}{l}0.0 \\
0.0\end{array}$ & $\begin{array}{l}0.0 \\
0.1\end{array}$ & $\begin{array}{l}0.0 \\
0.1\end{array}$ & $\begin{array}{l}0.0 \\
2.7\end{array}$ & $\begin{array}{l}1.4 \\
3.5\end{array}$ \\
\hline $3 / 28 / 55$ & $\begin{array}{l}\text { Tops } \ldots \ldots \ldots \ldots \ldots \\
\text { Rhizomes. }\end{array}$ & $\begin{array}{l}0.0 \\
0.0\end{array}$ & $\begin{array}{l}0.0 \\
0.0\end{array}$ & $\begin{array}{l}0.0 \\
0.0\end{array}$ & $\begin{array}{l}0.0 \\
3.3\end{array}$ & $\begin{array}{l}5.8 \\
4.8\end{array}$ \\
\hline \multicolumn{2}{|c|}{ MH plus 40 lbs. $\left(\mathrm{NH}_{4}\right)_{2} \mathrm{SO}_{4}$ : } & & & & & \\
\hline $1 / 15 / 55$ & $\begin{array}{l}\text { Tops.................... } \\
\text { Rhizomes..... }\end{array}$ & $\begin{array}{l}0.0 \\
0.0\end{array}$ & $\begin{array}{l}0.0 \\
0.2\end{array}$ & $\begin{array}{l}0.0 \\
0.9\end{array}$ & $\begin{array}{l}0.0 \\
1.3\end{array}$ & $\begin{array}{l}1.0 \\
3.8\end{array}$ \\
\hline $3 / 28 / 55$ & $\begin{array}{l}\text { Tops } \ldots \ldots \ldots \ldots \ldots \\
\text { Rhizomes.......... }\end{array}$ & $\begin{array}{l}0.0 \\
0.0\end{array}$ & $\begin{array}{l}0.0 \\
0.0\end{array}$ & $\begin{array}{l}0.0 \\
0.0\end{array}$ & $\begin{array}{l}0.0 \\
1.6\end{array}$ & $\begin{array}{r}10.2 \\
4.9\end{array}$ \\
\hline
\end{tabular}

* No data taken.

seemed to inhibit regrowth without inducing dormancy in the rhizomes. Nitrogen added eight days before the MH spray (culture No. 7) counteracted the dormancy-inducing action of $\mathrm{MH}$, and the plants produced as much top growth as the untreated control. However, there was also a large mass of dormant rhizomes in these cultures. In three instances (cultures Nos. 7, 9, and 11) added nitrogen induced some regrowth over and above that on the 
MH control (culture No. 6). On the other hand, when phosphate was added after $\mathrm{MH}$ spraying and turning, dormancy equal to, or greater than, the control was induced. From these results it seems improbable that addition of a nitrogen fertilization to a schedule involving $\mathrm{MH}$ spraying followed by tillage will add to the effectiveness. Possible use of phosphate might justify further testing.

This experiment ends our work on the combined treatment (MH spraying and tillage) on Bermudagrass. From this work it is evident that thorough tillage, performed four to eight days after $\mathrm{MH}$ spraying, provides the added

TABLE 13

MH SPRAYS COMBINED WITH TILLAGE AND FERTILIZER APPLICATIONS IN TWELVE TESTS ON BERMUDAGRASS. VALUES ARE TOTALS FOR FOUR CULTURES. OBSERVATIONS MADE MARCH 3, 1955

\begin{tabular}{|c|c|c|c|c|c|c|c|c|}
\hline \multirow[b]{2}{*}{$\begin{array}{c}\text { Culture } \\
\text { no. }\end{array}$} & \multicolumn{6}{|c|}{ Treatment } & \multicolumn{2}{|c|}{ Results } \\
\hline & Date & Operation & Date & Operation & Date & Operation & Regrowth & $\begin{array}{l}\text { Rhizomes } \\
\text { (pliable, } \\
\text { dormant) }\end{array}$ \\
\hline & & & & & & & $\mathrm{cm}$ & $g m$ \\
\hline 1 & $11 / 30 / 54$ & Turned & & & & & 13.1 & 0 \\
\hline 2 & $11 / 18 / 54$ & $\mathrm{NH}_{4}{ }^{+}$added & $11 / 30 / 54$ & Turned & & & 61.9 & 0 \\
\hline 3 & $11 / 18 / 54$ & $\mathrm{PO}_{4} \equiv$ added & $11 / 30 / 54$ & Turned & & & 13.7 & 0 \\
\hline 4 & $11 / 30 / 54$ & Turned & $12 / 1 / 54$ & $\mathrm{NH}_{4}{ }^{+}$added & & & 63.3 & 0 \\
\hline 5 & $11 / 30 / 54$ & Turned & $12 / 1 / 54$ & $\mathrm{PO}_{4}$ added & & & 3.1 & $\mathbf{0}$ \\
\hline 6 & $11 / 26 / 54$ & MH spray & $11 / 30 / 54$ & Turned & & & 0.5 & 10.2 \\
\hline 7 & $11 / 18 / 54$ & $\mathrm{NH}_{4}{ }^{+}$added & $11 / 26 / 54$ & MH spray & $11 / 30 / 54$ & Turned & 16.4 & 42.9 \\
\hline 8 & $11 / 18 / 54$ & $\mathrm{PO}_{4} \equiv$ added & $11 / 26 / 54$ & MH spray & $11 / 30 / 54$ & Turned & 1.0 & 46.8 \\
\hline 9 & $11 / 26 / 54$ & MH spray & $11 / 30 / 54$ & Turned & $12 / 1 / 54$ & $\mathrm{NH}_{4}{ }^{+}$added & 2.2 & 44.4 \\
\hline 10 & $11 / 26 / 54$ & MH spray & $11 / 30 / 54$ & Turned & $12 / 1 / 54$ & $\mathrm{PO}_{4} \equiv$ added & 0.1 & 48.2 \\
\hline 11 & $11 / 26 / 54$ & MH spray & $11 / 30 / 54$ & Turned & $12 / 8 / 54$ & $\mathrm{NH}_{4}{ }^{+}$added & 4.7 & 45.4 \\
\hline 12 & $11 / 26 / 54$ & MH spray & $11 / 30 / 54$ & Turned & $12 / 8 / 54$ & $\mathrm{PO}_{4} \equiv$ added & 0.5 & 50.5 \\
\hline
\end{tabular}

injury or upset required to convert into lethal action the prolonged dormancy induced by $\mathrm{MH}$. Field work in California, as well as thorough testing by Buchholtz (1954), Bibbey and Buckley (1954), Friesen and Walker (1954), Raleigh (1955), Vengris (1955), Zick and Buchholtz (1954), has confirmed this finding. The Naugatuck Chemical Division, U. S. Rubber Co., has developed recommendations for this treatment as presented in their Booklet No. 21-A.

One obvious advantage of this treatment over many other chemical methods is the fact that no toxic residue is left in the soil ; crops may be seeded in the treated area as soon as the tillage is completed and the seedbed prepared. There seems to be some evidence that a complete turning of the grass sod, which inverts the plants and thoroughly covers all rhizomes, is superior to rototilling, which breaks up the rhizome system and leaves portions mixed throughout the soil mass. In the latter treatment some portions of rhizomes are bound to be left exposed on the surface.

Some recent work by Delwiche and Wyler (1956) has indicated that turning of a grass sod alters the nitrogen relation of the soil and plants quite radically. From their data (table IV, page 121) it seems that inverting a mulch very materially increases microbial activity and results in greatly 
increased nitrogen fixation. Delwiche and Wyler interpret this increased nitrogen fixation on the basis of the greater substrate provided by the decaying grass. From our results it seems probable that the increased effectiveness of $\mathrm{MH}$ after plowing results from increased microbial action rather than from the increased nitrogen.

Relation of Maturity of Grasses to Effects of MH Treatment. Early in our studies with $\mathrm{MH}$ it seemed evident that the age or maturity of seedling plants was a determining factor in their response to this inhibitor (Currier and Crafts, 1950; Crafts, Currier and Day, 1950). In order to obtain more information on this point, cultures of seedlings of bluegrass, crabgrass, ripgut, foxtail, annual bluegrass and barnyardgrass were established, and four sets of cultures were sprayed at different dates (October 7, 14, 21, and 28, 1949). Figures 6 and 7 show some of the series. In each, comparison is made between an unsprayed control and cultures receiving $0.1,0.2,0.3$, and 0.4 per cent $\mathrm{MH}$ as an aqueous spray with 0.024 per cent Vatsol OT in each. From the photographs it is evident that in the case of grass seedlings increasing maturity increases the resistance of the plants to the toxicity of the chemical. This is most prominent on the bluegrasses where the most mature cultures were harmed very little by the 0.4 per cent concentration. Ripgut was next in order of susceptibility, followed by barnyardgrass and foxtail. Where it is desirable to control seedling grasses by an aqueous spray that leaves little or no toxic residue in the soil, MH would seem to be a logical choice.

\section{Translocation of $\mathrm{MH}$ in Bermudagrass}

One experiment on the translocation of $\mathrm{MH}$ in Bermudagrass was conducted, using the diethanolamine salt formulation. The experiment involved plants growing under various conditions of soil moisture: plants in soil near the permanent wilting percentage (PWP) before and during the experiment; plants in soil near the PWP before the experiment but well irrigated after the initial treatment; plants kept well irrigated both before and during the treatment period. The stem tips of some plants under each condition were immersed for 1-, 4-, 8-, and 24-hour periods; other plants were exposed to the MH by dipping a central portion of their stolons in the solution. The MH was 0.4 per cent in concentration.

The treatments were made on April 10, 1950, and observations were made April 11 and 19, May 8, and June 22, 1950. From these it seems that it takes at least four hours for significant amounts of $\mathrm{MH}$ to be absorbed by Bermudagrass stolons; about a month is required for appearance of symptoms; after two months, 4-, 8-, and 24-hour treatments induced dormancy and caused some contact injury in all nodes of the stolons above the treated region. Plants having ample moisture both before and during treatment gave the greatest response.

More recent work on translocation using $\mathrm{C}^{14}$-labled $\mathrm{MH}$ is described later.

\section{Physiological Tests on MH Uptake}

In order to obtain a clearer picture of the functions of uptake and movement of MH in plants, a series of physiological experiments have been made, using a variety of plant materials.

One test was carried out with young tomato plants growing in Hoagland's 


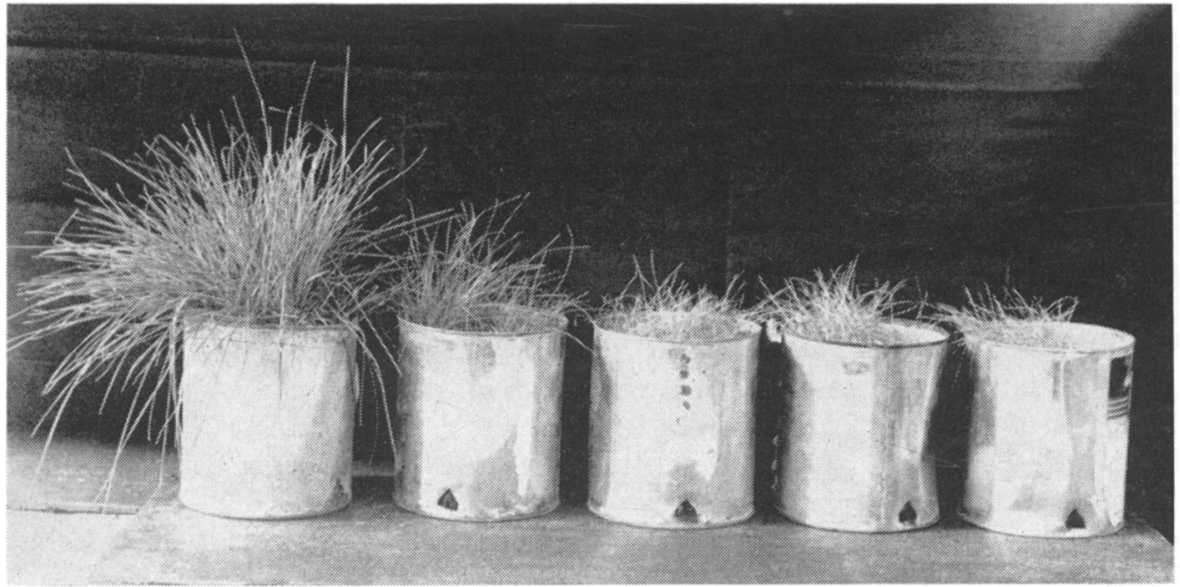

Kentucky bluegrass

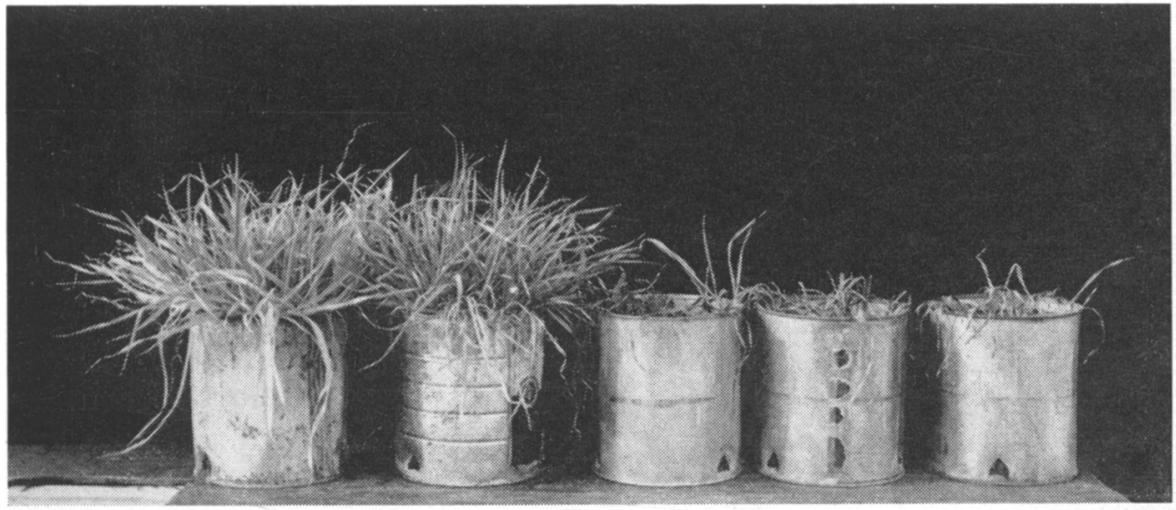

Bromus rigidus (ripgut)

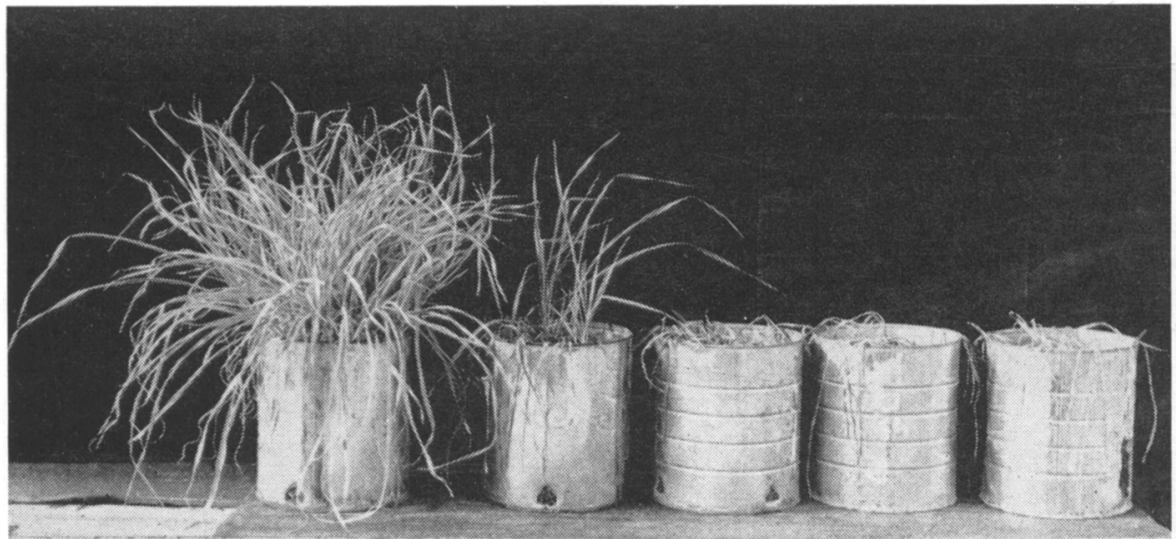

Hordeum murinum (foxtail) 


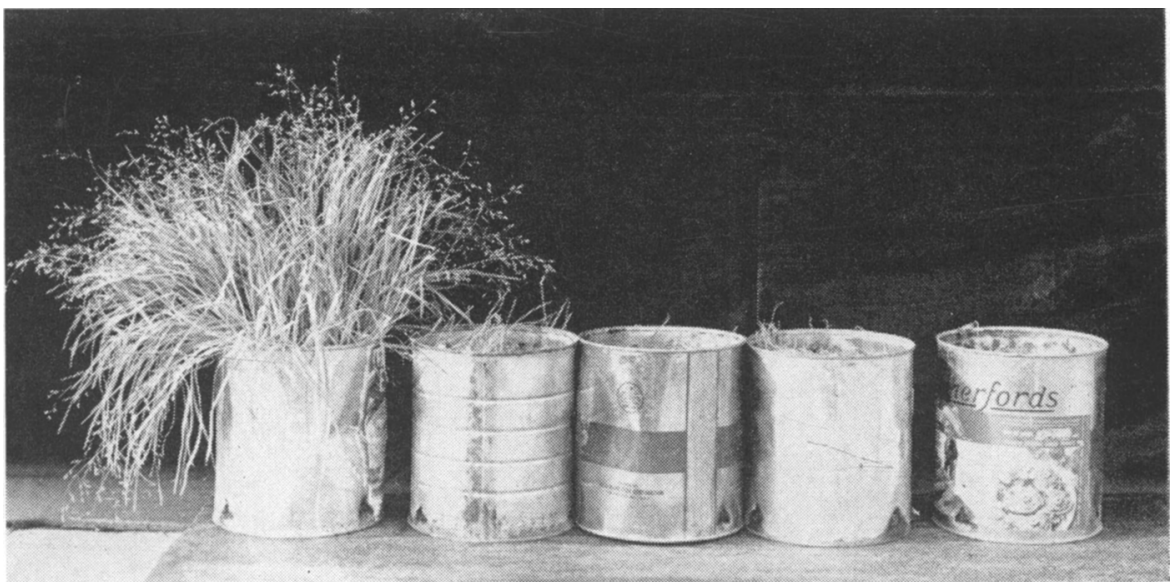

Poa annua (annual bluegrass)

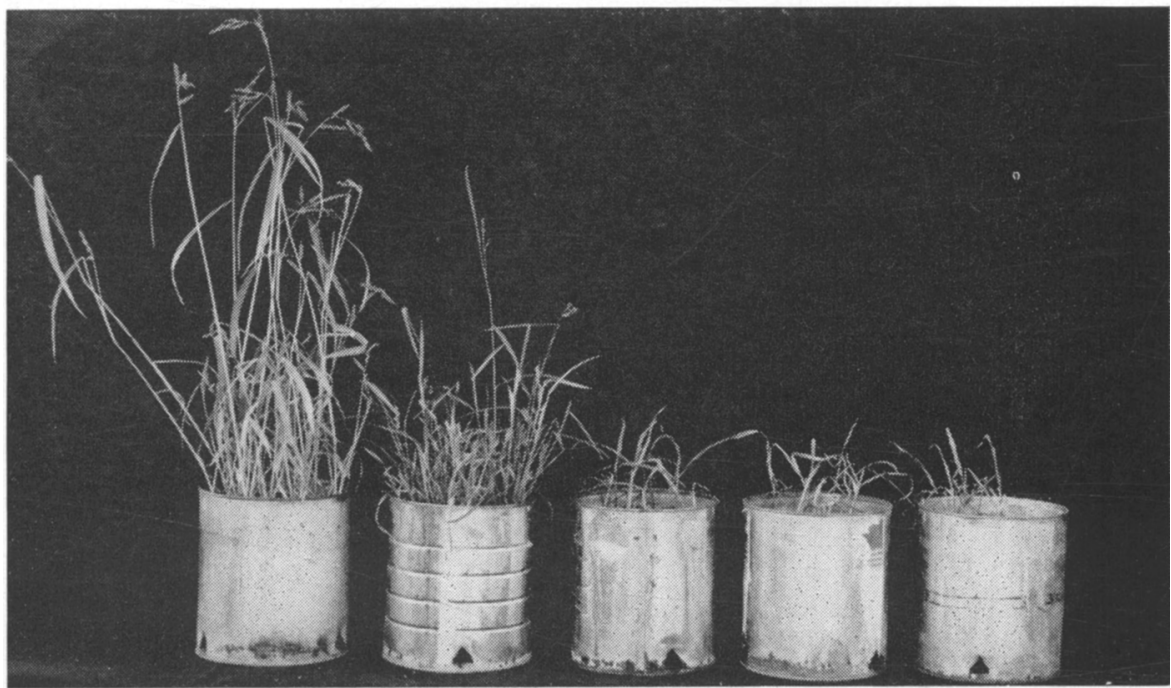

Echinocloa crus-galli (barnyardgrass)

Fig. 6. MH sprays applied to cultures of Kentucky bluegrass planted Sept. 16, 1949; Bromus rigidus (ripgut), Hordeum murinum (foxtail), and Poa annua (annual bluegrass) planted Sept. 20, 1949; and Echinocloa crus-galli (barnyardgrass) planted Sept. 23, 1949. Left to right: untreated control, MH 0.1 per cent; $\mathrm{MH} 0.2$ per cent, $\mathrm{MH} 0.3$ per cent, MH 0.4 per cent. All cultures sprayed Oct. 7, 1949, and photographed Nov. 14, 1949. 


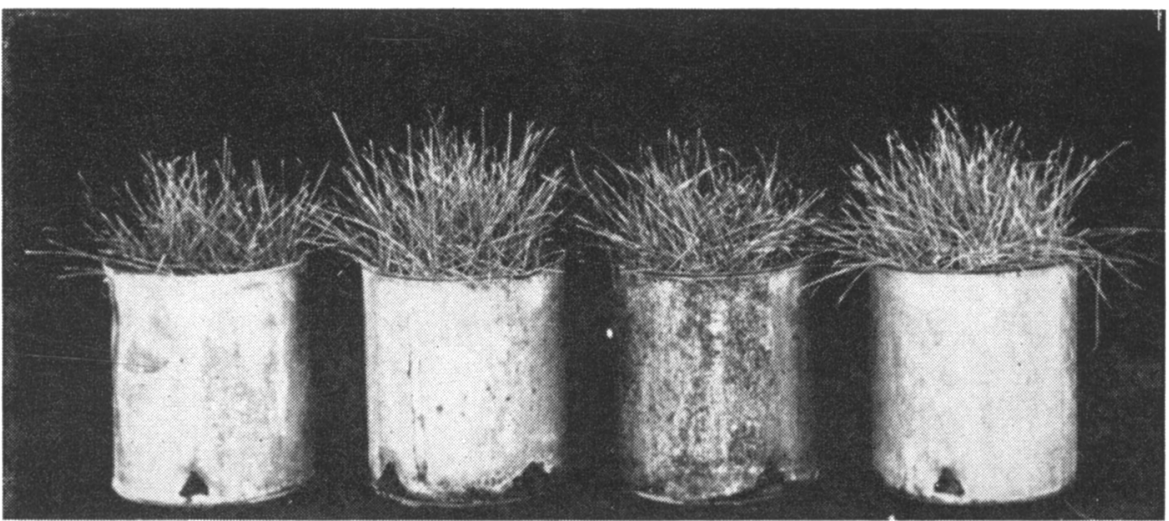

Kentucky bluegrass

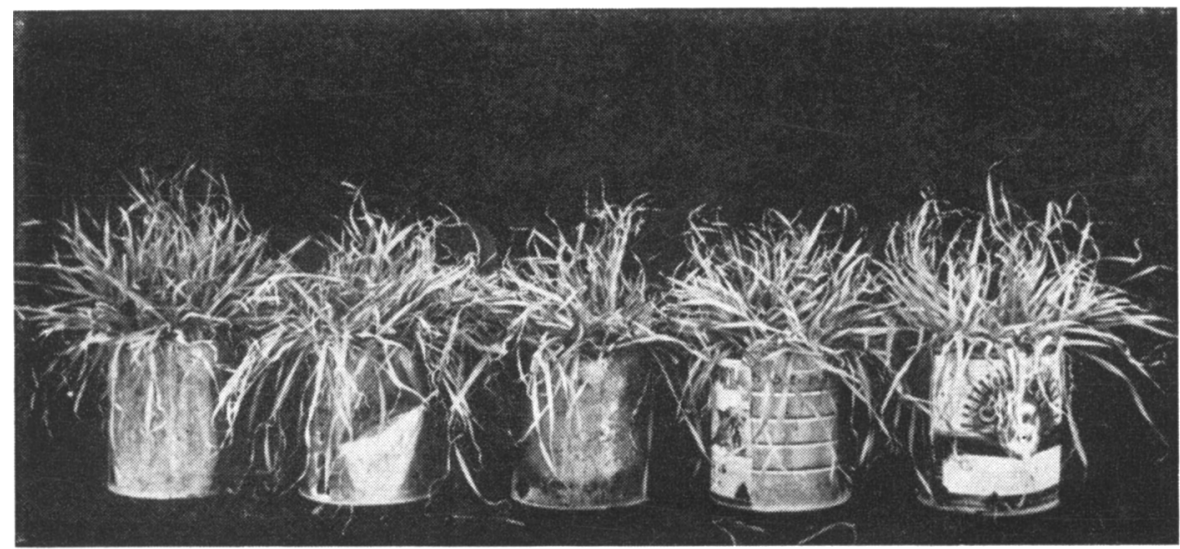

Bromus rigidus (ripgut)

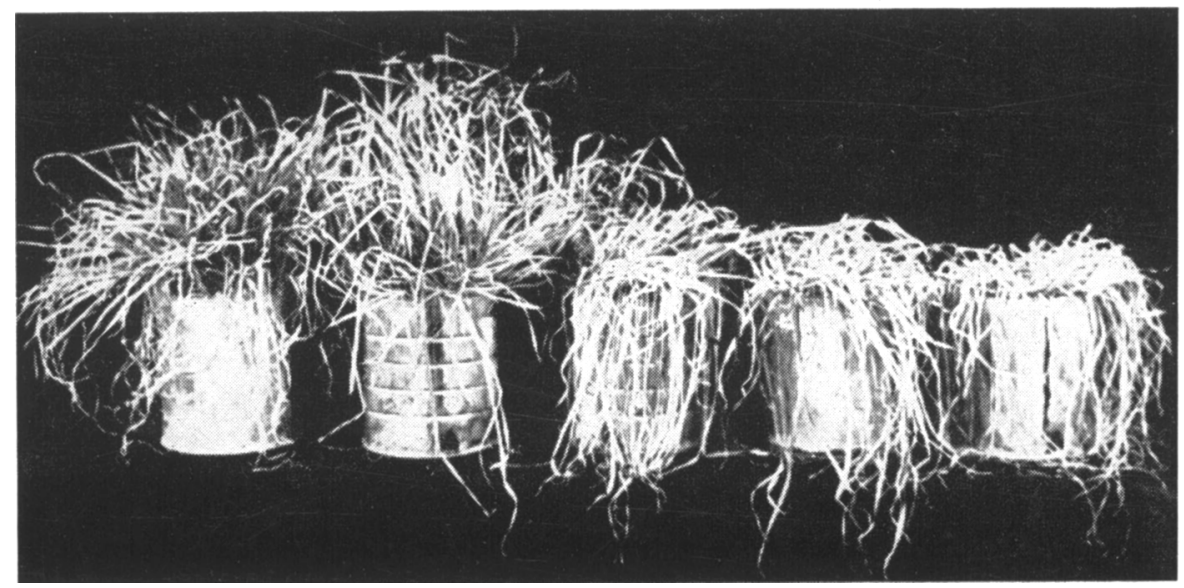

Hordeum murinum (foxtail) 


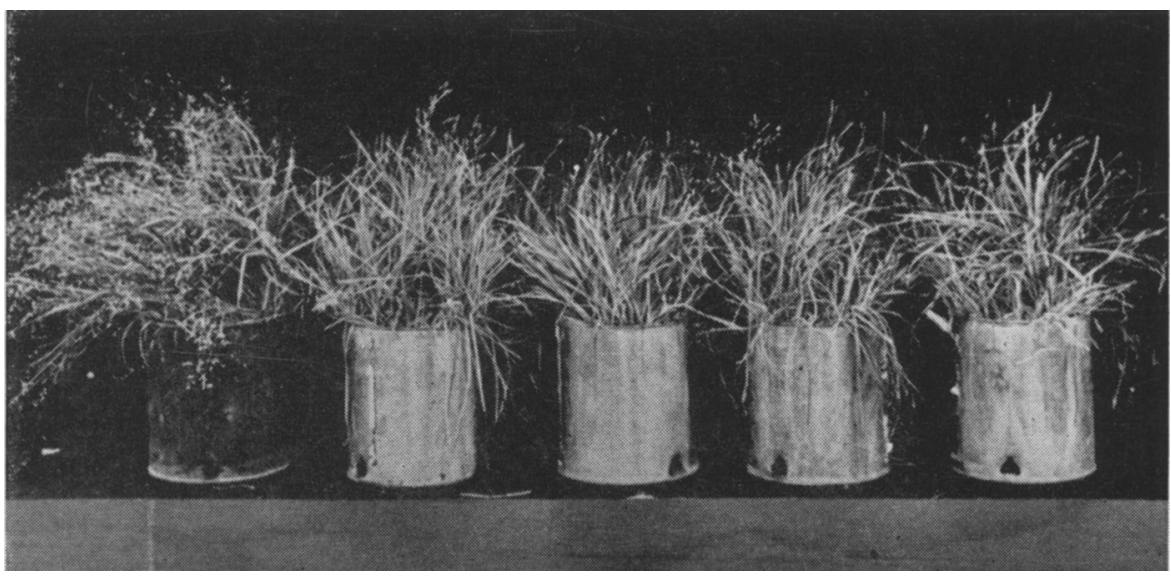

Poa annua (annual bluegrass)

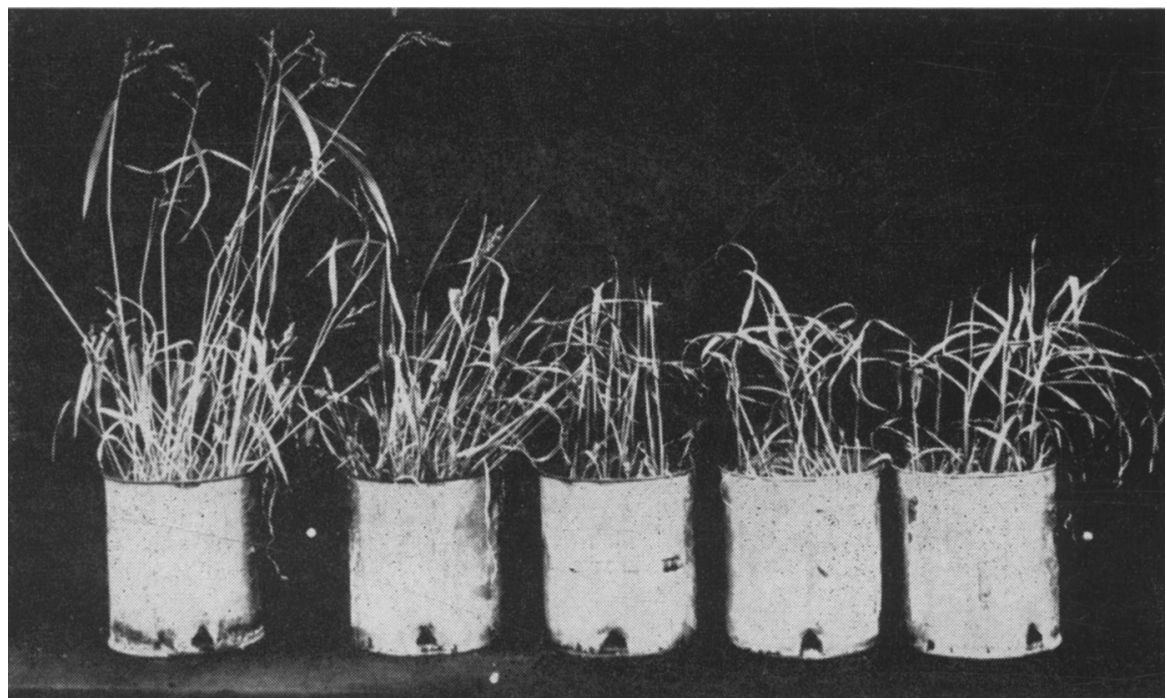

Echinocloa crus-galli (barnyardgrass)

Fig. 7. MH sprays applied to cultures of different ages. At spraying dates the cultures had attained the following ages: Kentucky bluegrass, 42 days; Bromus rigidus, 38 days; Hordeum murinum, 38 days; Poa annua, 39 days; Echinocloa crus-galli, 28 days. Left to right: untreated control, $\mathrm{MH} 0.1$ per cent, MH 0.2 per cent, MH O.3 per cent, MH 0.4 per cent. The older cultures were more resistant to the toxic action of $\mathrm{MH}$. 
solution. Since the days were short and the light not strong (December, 1954), the plants were placed under a bank of lights made up of slim-line fluorescent lights and mazda bulbs. Ten cultures were used, each having two plants. They were placed under the lights on December 22, 1954, and treated January 4, 1955. Treatment consisted of shifting the plants into jars containing 1.0 per cent $\mathrm{MH}$ for varying periods, then rinsing the roots thoroughly and replacing them in Hoagland's solution for the development of symptoms. The exposure times were $71 / 2,15$, and 30 minutes. One culture was retained in Hoagland's solution as a control. The culture solution was renewed each week after the treatment. Notes were taken on 14 different days during the 21-day examination period. At the end of the experiment the increases in leaf number and the height of plants were recorded and averaged. The values of these are presented in table 14 .

TABLE 14

EFFECT OF 1 PER CENT MH APPLIED TO ROOTS OF TOMATO PLANTS (Averages of four plants)

\begin{tabular}{|c|c|c|c|c|}
\hline Treatment & $\begin{array}{c}\text { Number of } \\
\text { leaves }\end{array}$ & $\begin{array}{l}\text { Plant } \\
\text { height }\end{array}$ & $\underset{\text { weight }}{\text { Root }}$ & $\begin{array}{c}\text { Top growth } \\
\text { weight }\end{array}$ \\
\hline & & $\mathrm{cm}$ & $g m$ & $g m$ \\
\hline Control. & 4.75 & 17.5 & 7.15 & 35.6 \\
\hline$\ldots \ldots \ldots \ldots \ldots \ldots \ldots \ldots \ldots \ldots \ldots$ & 5.25 & 24.0 & 6.10 & 42.5 \\
\hline$\ldots \ldots \ldots \ldots \ldots \ldots \ldots \ldots \ldots \ldots$ & 5.0 & 22.75 & 6.43 & 37.0 \\
\hline 30 minutes $\ldots \ldots \ldots \ldots \ldots \ldots \ldots \ldots \ldots \ldots \ldots \ldots$ & 2.0 & 8.75 & 5.0 & 28.4 \\
\hline
\end{tabular}

From these figures it is apparent that during the 30-minute exposure the roots absorbed enough $\mathrm{MH}$ to appreciably inhibit growth of tomato plants. The shorter exposures apparently stimulated growth somewhat. The symptoms that were apparent at the end of the experiment were similar to those brought on by spraying the foliage. They resemble to a certain extent symptoms of shoestring virus (see Crafts, Currier and Day, 1950, figs. 13, 14, and 15). Evidently the metabolism of the plants is seriously disturbed. Similar symptoms have been observed on tomato plants treated with low concentrations of 2,4-D and on plants severely pruned just before blossoming. One additional observation was that the treated plants used considerably less water (control, 1,755 ml; 71/2-min. treatment, 1,412 ml; and 30-min. treatment, $1,057 \mathrm{ml}$ ).

\section{Comparison of $\mathrm{MH}$ and Dalapon}

When dalapon (2,2-dichloropropionic acid, sodium salt) was introduced as a foliage-absorbed, translocated grass-killer, it seemed of interest to test it in comparison with MH. In several types of greenhouse tests the effectiveness and pattern of response of the two were compared (Currier, 1954). $\mathrm{MH}$ as the diethanolamine salt was used at 1.0 per cent active basis. Dalapon was used as a 1.0 per cent solution. Each solution contained 0.1 per cent Vatsol OT.

Foliage Spray Tests. Barley plants, 12 per pot in replicates of 5 in the second-leaf stage, and actively growing Bermudagrass plants in No. 10 cans were sprayed to run-off in standardized test procedures. The initial response 
of barley to dalapon was more rapid than to $\mathrm{MH}$. A slight burning of the leaves was noted; growth abnormalities developed as later responses; leaves tended to fuse, to buckle, and to remain tubular instead of flattening normally. Response to $\mathrm{MH}$ was typically slower, the leaves becoming thicker, darker green, more brittle, and mottled, turning eventually to yellow. Treatments with both chemicals were eventually lethal. Harvest of the shoots four weeks after spraying yielded the data in table 15. Fig. 8 shows representative plants 17 days after treatment.

TABLE 15

RESULTS OF MH SPRAY APPLIED TO BARLEY FOLIAGE

\begin{tabular}{|c|c|c|c|}
\hline & Untreated & MH & Dalapon \\
\hline 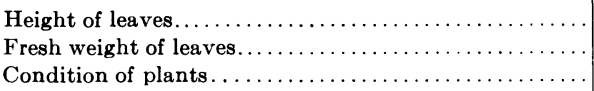 & $\begin{array}{l}35.6 \pm 0.5 \mathrm{~cm} \\
20.8 \pm 1.5 \mathrm{gm} \\
\text { boot stage }\end{array}$ & $\begin{array}{r}26.0 \pm 0.4 \mathrm{~cm} \\
2.6 \pm 0.2 \mathrm{gm} \\
\text { dead or dying }\end{array}$ & $\begin{array}{l}21.6 \pm 0.8 \mathrm{~cm} \\
0.9 \pm 0.2 \mathrm{gm} \\
\text { dead }\end{array}$ \\
\hline
\end{tabular}

On the Bermudagrass cultures in No. 10 eans, sprays of both $\mathrm{MH}$ and dalapon gave complete inhibition, but the response to dalapon was more necrotic. Four months after treatment no growth had occurred in any of the

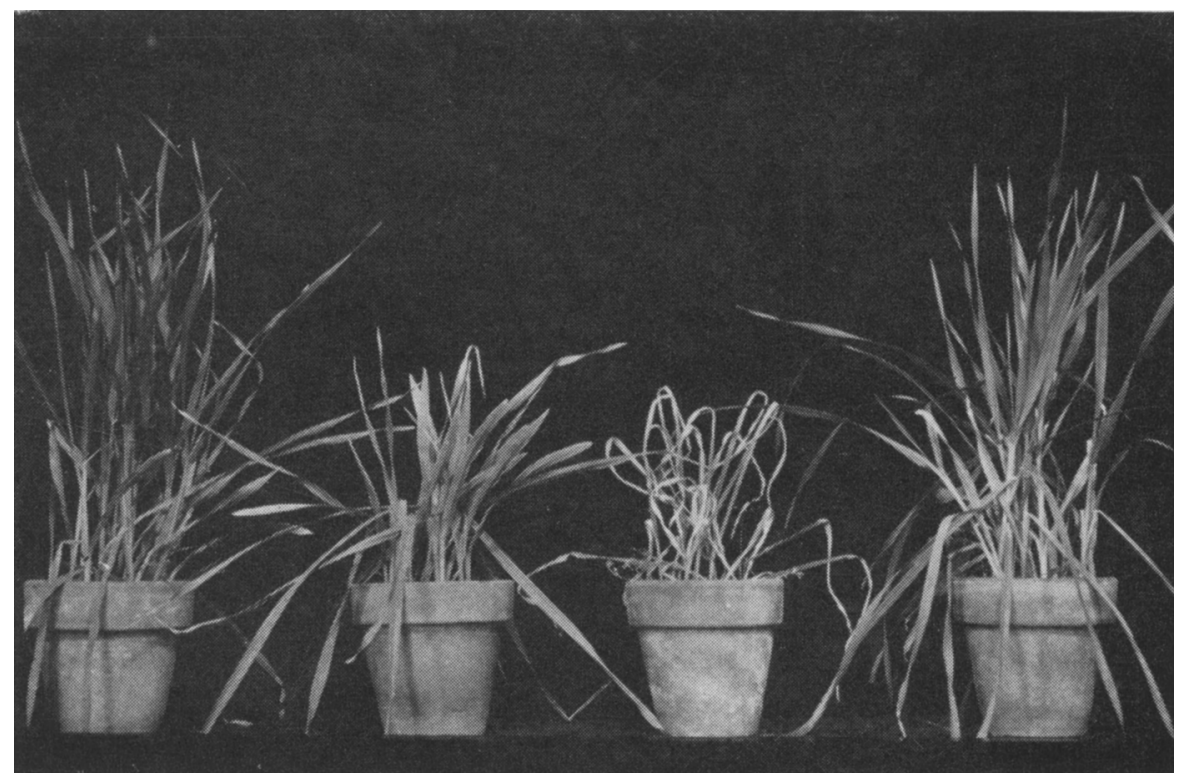

Fig. 8. Barley plants treated in the second-leaf stage, 13 days after planting, photographed 17 days after treatment. Left to right: control, MH 1.0 per cent (typical injury), dalapon 1.0 per cent (dead or dying), second control.

plants. Six weeks later, regrowth had occurred in the dalapon-treated plants, although 98 per cent of the foliage was dead. There was no regrowth on the MH-treated plants.

Dip Tests. Leaf- and root-dip techniques were used to compare the amounts of herbicide absorbed in a given time, as indicated by subsequent growth 
responses. Roots of tank-grown (Hoagland's) barley plants in the first-leaf stage were dipped in test solutions for 15 minutes, washed in running water 10 seconds, then returned to the tank. The plants were treated in groups of 10. Test solutions contained 1.0 per cent growth regulator ( $\mathrm{MH}$ or dalapon) and $0.01 \mathrm{M}$ phosphate buffer, $\mathrm{pH}$ 6.0. Vatsol OT at 0.05 per cent was added to one series. In other tests, leaves were dipped in such solutions for 5 and for 30 minutes, during which time roots were protected from drying by wrapping them with Parafilm. Growth of roots and leaves was observed over a period of 20 days, and the extent of growth inhibition after this period of time was recorded. Table 16 presents some of the leaf-dip results. Repre-

\section{TABLE 16}

GROWTH INHIBITION IN BARLEY EXPRESSED AS PERCENTAGE OF GROWTH OF UNTREATED PLANTS

(Leaves of two groups of ten plants each were dipped for five minutes, then rinsed. Data were taken 20 days after treatment.)

\begin{tabular}{|c|c|c|c|c|}
\hline \multirow{2}{*}{ Treatment } & \multicolumn{2}{|c|}{ Leaves } & \multicolumn{2}{|c|}{ Roots } \\
\hline & Weight & Height & Weight & Length \\
\hline & $\%$ & $\%$ & $\%$ & $\%$ \\
\hline МH $1.0 \% \ldots$ & 45 & 64 & 56 & 71 \\
\hline MH $1.0 \%$-Vatsol $0.05 \% \ldots \ldots \ldots$ & 10 & 32 & 20 & 52 \\
\hline Dalapon $1.0 \% \ldots \ldots \ldots \ldots \ldots \ldots \ldots$ & 89 & 92 & 107 & 114 \\
\hline Dalapon $1.0 \%$-Vatsol $0.05 \%$. & 4 & 32 & 31 & 70 \\
\hline
\end{tabular}

sentative plants of the root-dip series at harvest time are shown in Figure 9 at time of harvest, 20 days after treatment.

With both leaf- and root-dip methods typical foliage responses to $\mathrm{MH}$ and dalapon developed, as described in results of foliage-spray tests. This suggests that both substances move readily within the plant. In short treatments, whether root-dip or leaf-dip, the toxic action of dalapon seems to be localized in the leaves, whereas $\mathrm{MH}$ inhibition is more systemic. Longer treatments reduce this differential behavior. The addition of a surfactant markedly increased leaf absorption of both chemicals. Surfactants promoted root absorption of dalapon, to a greater extent than of MH. The surfactant alone at 0.05 per cent exerted no effect or was only slightly toxic. Increase of root absorption by a surfactant is of interest, since roots are readily wetted by water. In all probability the action must be primarily on the protoplasm of root cells. This is in contrast to foliage absorption, where the plasma membrane is only one of the lipid surfaces on which surfactants can exert their effect.

Drop Tests. The foliage-applied drop test is another method of accurately determining the amount of chemical applied. Tank-grown Hubbard squash seedlings were treated when the cotyledons had fully expanded and the first leaf was 1 to $2 \mathrm{~cm}$ long. A $0.02-\mathrm{ml}$ drop of test solution was placed in the center of the upper surface of one cotyledon, the drop containing 1.0 per cent of either $\mathrm{MH}$ or dalapon, with no surfactant. After three weeks, control plant stems had grown 4 to 5 feet. MH-treated plants were severely stunted and 
deformed, with growth limited to 2 to $3 \mathrm{~cm}$ above the cotyledons. Dalapon caused no observable effects.

Kidney bean plants in the unifoliate leaf stage were also used in the drop test. A 0.02-ml drop was placed on the top center midrib region of one leaf. Both chemicals inhibited growth, MH more than dalapon. There was a tendency of dalapon-treated plants to grow out of the inhibition to a greater extent than MH-treated plants. Thirty days after the treatment, untreated plants were setting fruit. For both $\mathrm{MH}$ and dalapon, plants showed loss of

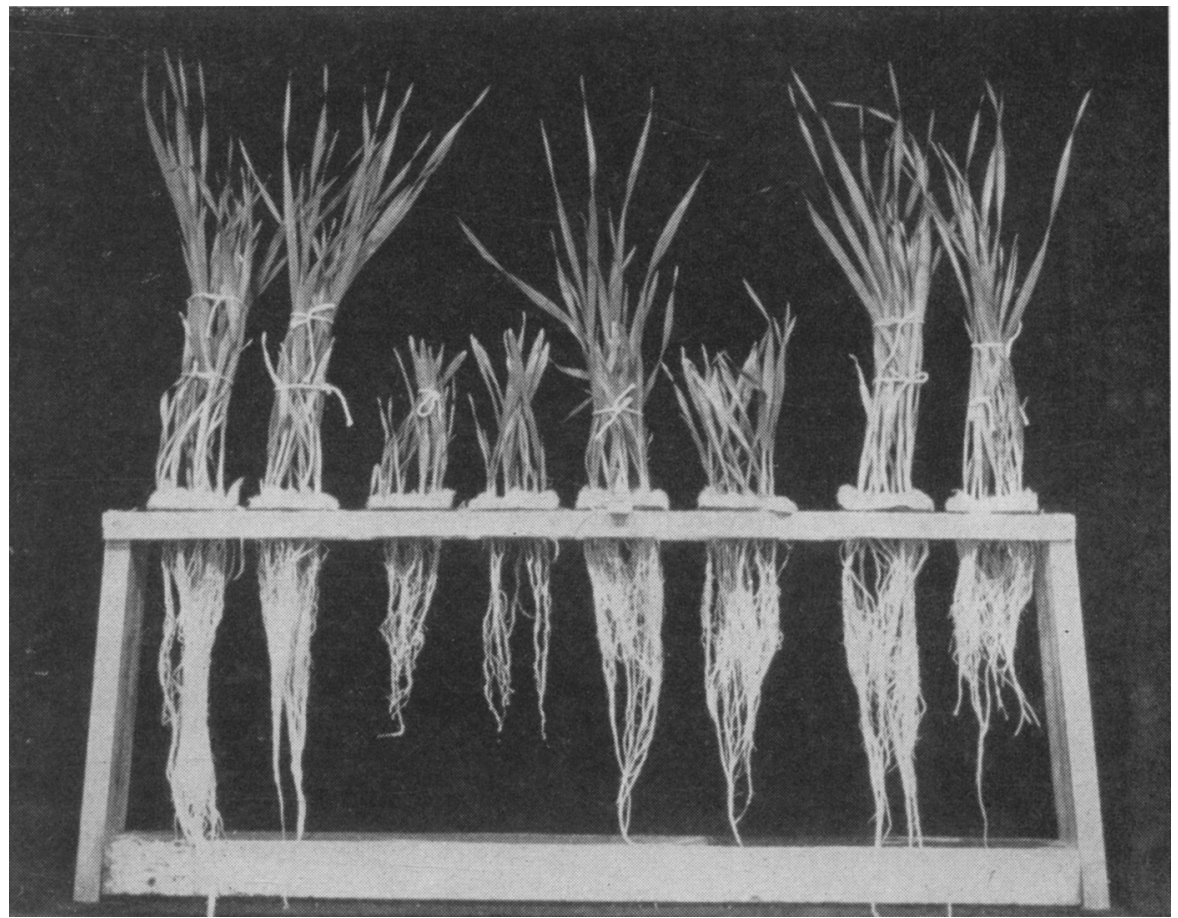

Fig. 9. Barley, tank-grown, treated with $\mathrm{MH}$ and dalapon by dipping roots into test solutions for 15 minutes, then rinsing, and returning to tanks. Left to right: control, Vatsol OT at 0.05 per cent, $\mathrm{MH}$ at 1.0 per cent, $\mathrm{MH}$ at 1.0 per cent plus Vatsol at 0.05 per cent, dalapon at 1.0 per cent, and dalapon at 1.0 per cent plus Vatsol at 0.05 per cent. The two plants on the right were treated with an ineffective compound not considered in this report. All solutions contained $0.01 \mathrm{M}$ phosphate $\left(\mathrm{KH}_{2} \mathrm{PO}_{4}-\mathrm{K}_{2} \mathrm{HPO}_{4}\right)$ mixture, $\mathrm{pH}$ 6.0. Photographed 15 days after dipping.

apical dominance, with numerous axillary shoots; there were no flowers. MH produced mottling, dalapon marginal chlorosis of older leaflets. A summary of results is shown in table 17 , and representative plants in figure 10 .

The importance of these results is that a very small amount of either chemical can be absorbed and can exert growth-regulating action. In contrast to 2,4-D and similar substances, neither dalapon nor MH caused bending of the stem of bean plants.

On the basis of these limited tests, MH and dalapon apparently have 
several similar effects on plants. Both seem to be slow-acting translocated growth regulators; in small amounts they inhibit apical dominance (bean) and stimulate axillary growth. Both cause formative effects under certain conditions. The chemicals also differ in several ways. Compared with $\mathrm{MH}$, dalapon is visibly more rapidly absorbed by leaves, causes burning of leaf tips as an acute symptom, and affects leaf growth at first more than root

TABLE 17

FOLIAGE-APPLIED DROP TEST USING BEAN PLANTS. DATA TAKEN 30 DAYS AF'TER TREATMENT WITH A 0.02-ML DROP OF 1 PER CENT MH OR 1 PER CENT DALAPON

\begin{tabular}{|c|c|c|}
\hline Treatment & $\begin{array}{c}\text { Mean plant } \\
\text { height }\end{array}$ & $\begin{array}{c}\text { Mean weight } \\
\text { of shoot }\end{array}$ \\
\hline & $\mathrm{cm}$ & $g m$ \\
\hline Control. & $32.6 \pm 1.1$ & $22.7 \pm 1.1$ \\
\hline MH..... & $19.5 \pm 0.7$ & $16.0 \pm 1.2$ \\
\hline Dalapon $\ldots \ldots \ldots \ldots \ldots \ldots \ldots$ & $29.9 \pm 1.5$ & $24.9 \pm 0.6^{*}$ \\
\hline
\end{tabular}

* Not significant at 5 per cent level.

growth. There is variation in the occurrence of abnormal growth, as is shown by squash and barley. Taken together, the results suggest that the two chemicals act in some fundamentally different way to cause inhibition.

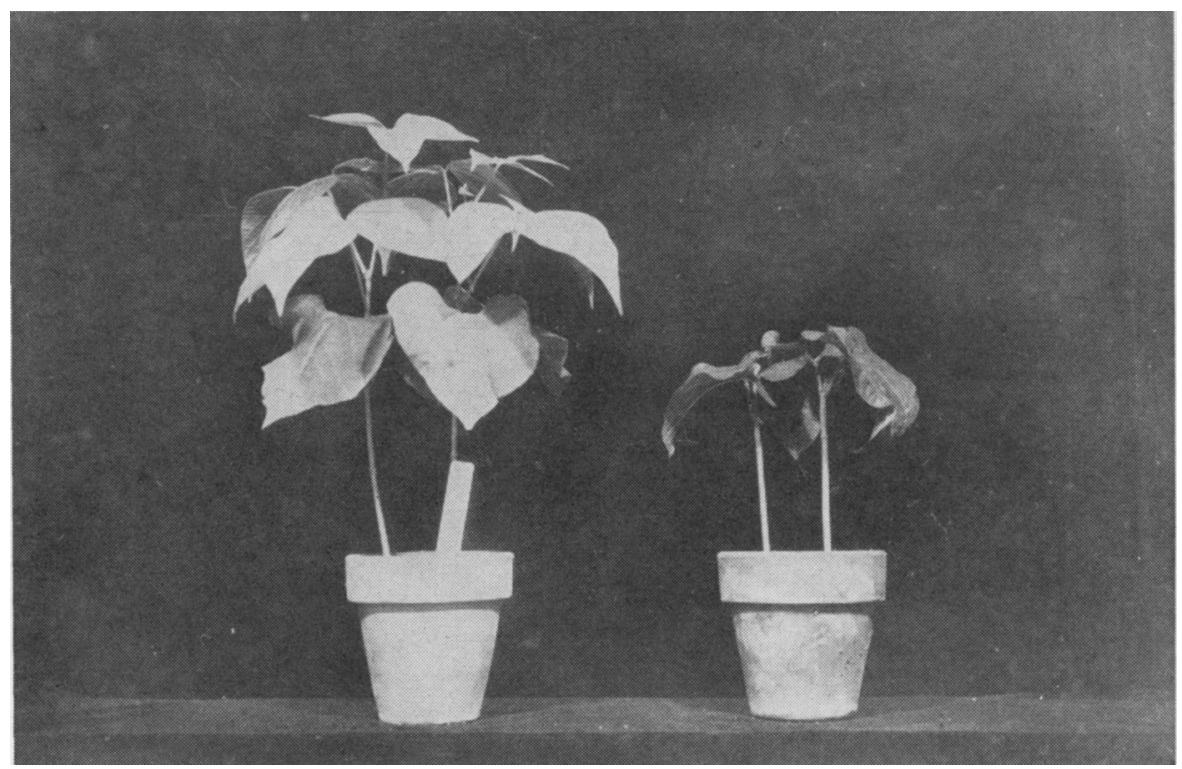

Fig. 10. Response of bean to one $0.02-\mathrm{ml}$ drop of 1.0 per cent MH (DEA salt), compared with untreated control (left). Photographed 25 days after treatment.

The results of tests incorporating a surfactant point to the importance of herbicidal additives in promoting penetration of these two substances. Vatsol OT appears to be one of the most promising tested. 


\section{Studies with Labeled Compounds}

With labeled tracers becoming available, we have turned to these in our studies on absorption and translocation. Our results indicate that $\mathrm{C}^{14}$-labeled $\mathrm{MH}$, hereafter designated as $\mathrm{MH}^{*}$, is absorbed through both upper and lower surfaces of the leaf of Zebrina. Since the upper surface lacks stomata, this proves that MH can move through cuticle into the mesophyll cells. This is in accord with the generally accepted principle that aqueous solutions in general do not penetrate stomata and stomatal chambers unless a pressure gradient is established that forces them in, or unless the surface tension is

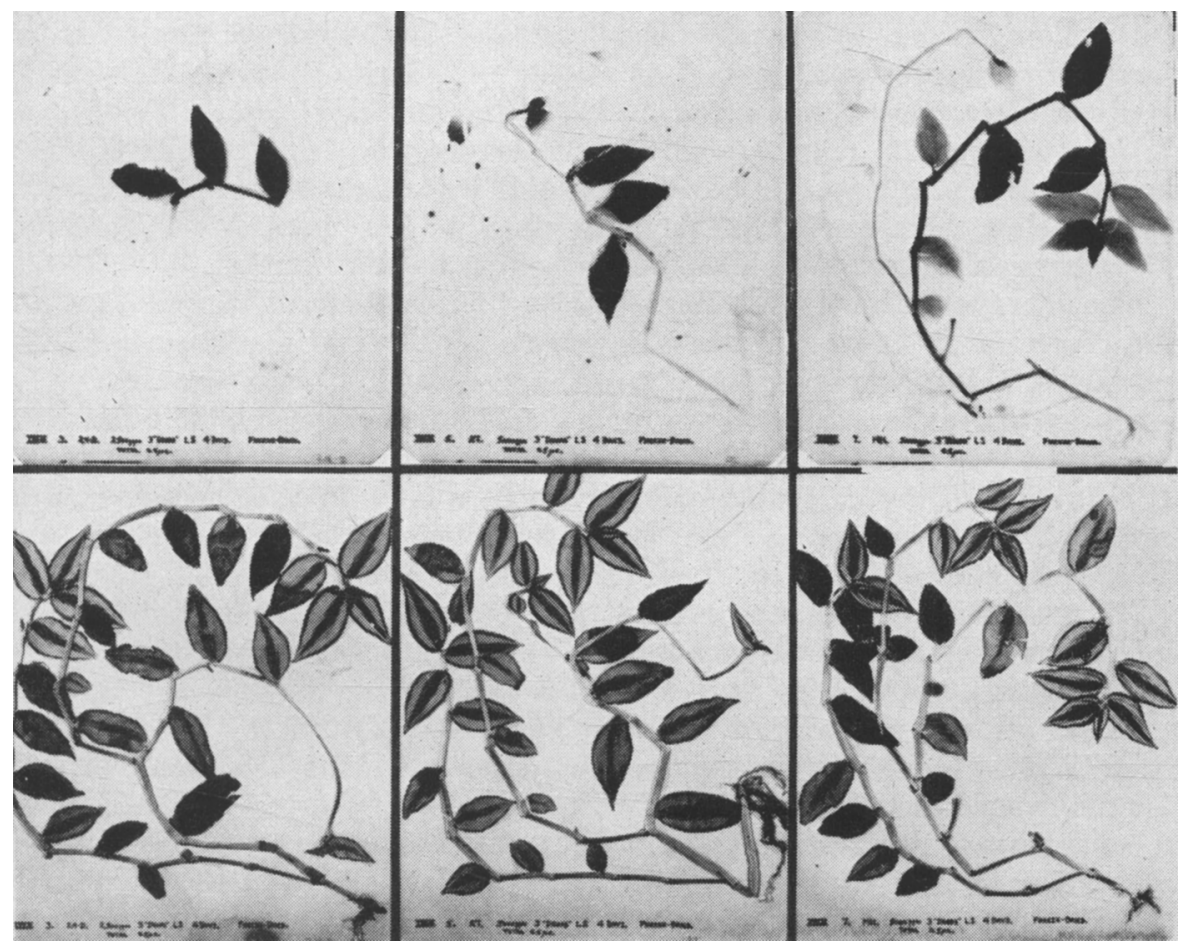

Fig. 11. Translocation of labeled herbicides in Zebrina: left, 2,4-D*; center, ATA*, right, $\mathrm{MH}^{*}$. Upper row, autoradiographs; lower row, photographs of the respective treated plants. The plants were mature, growing in depleted soil cultures. Treatment was on three leaves (lower surface) in each case; treatment time, 4 days; dosage, 0.5 microcuries. The plants were freeze-dried in preparation for autographing.

drastically reduced. The frequently observed greater absorption by lower leaf surfaces is apparently related to a thinner cuticle as well as to the presence of stomata.

On the basis of earlier studies using $\mathrm{C}^{14}$-labeled material (Crafts and Yamaguchi, 1958), MH apparently moves slowly through cuticle and mesophyll depending upon the concentration; high dosage speeds up the inward movement, and a certain threshold quantity must be applied to cause movement into the phloem. 
Study of the autoradiographs leads to the conclusion that once $\mathrm{MH}$ enters the phloem of the leaf, it moves downward very freely and throughout the plant. Figure 11 shows Zebrina plants that were treated on three leaves each with $\mathrm{MH}^{*}$, aminotriazole* (ATA), and 2,4-D*. From the autoradiographs it is apparent that movement of $2,4-\mathrm{D}^{*}$ was very limited, movement of ATA* was intermediate, and movement of $\mathrm{MH}^{*}$ was much more extensive, $\mathrm{MH}^{*}$ reaching practically every part of the treated plant.

This leads to four important assumptions with respect to the distribution of such chemicals. (1) They are able to move through the living phloem without hindrance due to plugging of sieve tubes. This is remarkable in view of their inherent toxicity and the fact that the sieve tubes are basically sensitive cells (Currier, Esau, and Cheadle, 1955). (2) Absorption is a crucial factor with respect to the extent of movement. Figure 11 shows that 2,4-D* is absorbed to the greatest extent, ATA* next, and MH* least. (3) Because $\mathrm{MH}^{*}$ was present in untreated mature leaves whereas such leaves were bypassed by ATA*, it seems likely that MH leaks from the phloem into the xylem below these leaves and then circulates in the plant. (4) Metabolism of a chemical in plant tissues places a ceiling on distribution.

The interpretation in (3) above is based on established views regarding the direction of solute movement in plants. Transport in phloem is either upwards or downwards; transport in the xylem is normally upwards only. Although direct proof is lacking, it is confidently assumed that downward movement occurred in the phloem under the conditions of the experiment. It is further suggested that 2,4-D* movement was limited to the phloem and restricted by absorption in living cells; $\mathrm{ATA}^{*}$ moved in the phloem but was not restricted by absorption, hence distribution was much more extensive; MH* moved initially in the phloem to roots and into the xylem and the upward-moving transpiration stream, labeling the leaves along the stem that were bypassed by ATA.*

We know from the work of Weintraub et al. (1952) that 2,4-D* is metabolized in plants and that radioactive $\mathrm{CO}_{2}$ is lost. This might account in part for the limited distribution of 2,4-D* in the Zebrina plant of figure 11. Such loss amounts to detoxification and may explain the frequent failure of 2,4-D as a killer of deep-rooted perennial weeds and woody plants. $\mathrm{MH}$, on the other hand, apparently moves relatively freely once it is in the phloem and tends to become thoroughly distributed within the plant body. Furthermore, as indicated by this experiment, it must not be subject to rapid breakdown. This probably explains why Bermudagrass plants may remain dormant for considerably more than a year after MH treatment. Sometimes such plants eventually die, but often they resprout, producing normal shoots, and become completely re-established within a few weeks once the dormancy is broken. Apparently, if killing is desired, an additional action is needed, and at present plowing or thorough tillage is the cheapest and most effective treatment to accomplish this. Continued dormancy and eventual death can also result from continued periodic sprayings.

\section{DISCUSSION}

When the possible herbicidal properties of $\mathrm{MH}$ were first pointed out in 1950 (Currier and Crafts), this chemical was the only translocated hormone-like material available for killing grasses. Since such a chemical has so many 
obvious uses in weed control, it seemed that its development constituted a definite challenge. Since then dalapon and aminotriazole have been introduced, both of which are possible translocated grass-killers. For this reason it seems desirable now to make a comparative evaluation of these materials and see where we stand with respect to their relative usefulness. Such evaluation must consider the effectiveness of these chemicals under field conditions; various aspects of their use, such as speed and completeness of action; possible soil residue and plant residue problems; and the economics of their use.

From the research described in this paper it is evident that $\mathrm{MH}$ is primarily a dormancy-inducing agent. It is presently used to prevent sprouting of onions and potatoes, to induce dormany in grass and shrubs, to prevent suckering of tobacco, and to control quackgrass and wild onions and garlic. In these latter instances the final action is dependent not upon an inherent phytotoxicity, but in the case of quackgrass upon a tillage operation that fatally disturbs the metabolism of the grass rhizomes, and in the case of onions and garlic upon prevention of reproduction by stopping the production of bulblets.

Obviously, MH has a place among agricultural chemicals as an inducer of dormancy. If we realize fully the significance of this fact we should appreciate why it has failed in many instances as a grass-killer. If it had the inherent phytotoxicity required to kill perennial grasses, there seems little doubt that it would injure potatoes and onions beyond usefulness and cause appreciable damage in lawns and tobacco and other situations where it is used to induce dormancy.

Accepting, then, the logical role of $\mathrm{MH}$ as an inducer of dormancy, it seems understandable why tillage or some other supplementary action is necessary in order to kill perennial grasses. Work reported here and by Buchholtz and others indicates that plowing or tillage of some sort is the cheapest supplement known at present. Oil sprays are less effective, undoubtedly because they are not translocated to the sites where resprouting starts.

While a search for more effective chemical supplements might be rewarding, it seems evident that any such chemical must enter and translocate in plants freely, that it must not be subject to rapid detoxification, and that presumably it must function in some way to deplete food reserves already carried to a very low level by the prolonged dormancy induced by the MH. 2,4-D does not seem promising in this role; aminotriazole might be more effective. Dalapon applied through the soil might function; applied through the tops, its apparent lack of free movement out of leaves (Wilkinson, 1956) might be a weakness.

A discussion of the relative merits of aminotriazole and dalapon as grasskillers is not appropriate to this study. Apparently certain selectivities are functioning among these materials to influence their effectiveness on different plant species. Only thorough, careful testing can tell us just where each will find its ultimate niche. In this work the use of labeled chemicals in studies on uptake and distribution may greatly accelerate the finding of answers to the various questions involved. 


\section{SUMMARY}

Maleic hydrazide $(\mathrm{MH})$ reduces bean bending resulting from 2,4-D treatment, apparently by inhibiting growth.

MH is effective by absorption through both leaves and roots.

Tests on formulation proved that surfactants and humectants intensify the effects of $\mathrm{MH}$ on plant growth, probably by improving penetration and by maintaining the chemical in a liquid film on the leaf.

$\mathrm{MH}$ does not follow the same pattern of response related to $\mathrm{pH}$ of the formulation as is found with dinitro compounds and 2,4-D. Water-soluble forms of $\mathrm{MH}$ are most effective, and high humidity promotes absorption. $\mathrm{MH}$ apparently enters the plant through an aqueous pathway.

Oil carriers proved less effective than aqueous ones for $\mathrm{MH}$, but aftertreatments with aromatic oils increased the effectiveness of MH treatment. Repeated sprays of MH increased effectiveness, as did follow-up applications of sodium chlorate and trichloracetic acid.

MH-induced dormancy was more prolonged in old, well-established Bermudagrass cultures than in new ones.

Simulated tillage treatments increased the effectiveness of MH very materially.

MH sprays on annual grass cultures of different states of maturity proved that young plants respond more than old ones.

Tomato plants absorbed enough MH from culture solutions to be appreciably inhibited when exposure time was 30 minutes.

Comparative tests with $\mathrm{MH}$ and dalapon proved that these two grass-killers have different toxic effects. MH induces deep dormancy, whereas dalapon causes formative responses and in high concentration, necrosis. Both are readily absorbed by leaves and translocated.

Tests with $\mathrm{C}^{14}$-labeled $\mathrm{MH}$ prove that this chemical moves relatively freely within plants and possibly leaks from the phloem to the xylem and hence circulates within these systems.

\section{ACKNOWLEDGMENTS}

The authors are especially indebted to the Naugatuck Chemical Division, U. S. Rubber Co., for supplies of maleic hydrazide in many formulations and for carbon ${ }^{14}$-labeled $\mathrm{MH}$. Other herbicides and herbicidal additives used in these studies were furnished by the American Chemical Paint Company, American Cyanamid Company, Atlas Powder Company, Carbide and Carbon Chemicals Division of Union Carbide Company, Colloidal Products Corporation, Dow Chemical Company, Niagara Chemical Division of Food Machinery and Chemical Corporation, Rohm and Haas Company, Standard Oil Company of California, Tidewater Associated Oil Company.

\section{LITERATURE CITED}

Anonymous

1955a. Absorption studies of maleic hydrazide by plants. Bethany Information Sheet No. 88. Nov. 1, 1955.

1955b. Tobacco sucker control. Ortho Field News. 55 (1). 
Bibbey, R. O., and E. H. Buckley

1954. The effect of straw mulching, surface black fallowing, and tillage following applications of $\mathrm{MH}$ to quackgrass. Eleventh Annual North Central Weed Control Conf. Res. Rpt. 11:2.

BuchHoltz, K. P.

1953. Control of quackgrass and annual weeds in corn with herbicides. Tenth Annual North Central Weed Control Conf. Res. Rpt. 10:2.

1954. Control of quackgrass by use of maleic hydrazide, 2,2-dichloropropionic acid and 3-amino-1,2,4-triazole combined with tillage. Eleventh Annual North Central Weed Control Conf. Res. Rpt. 11:3.

Crafts, A. S., H. B., Currier, and B. E. Day

1950. Response of several crop plants and weeds to maleic hydrazide. Hilgardia 20(4): $57-80$.

CURRIER, H. B.

1954. Greenhouse tests with maleic hydrazide and Dalapon. Fourteenth Western Weed Control Conf., Research Progress Report, p. 142-144.

Currier, H. B., and A. S. Crafts

1950. Maleic hydrazide, a selective herbicide. Science 111:152-153.

Currier, H. B., B. E. DAY, and A. S. Crafts

1951. Some effects of maleic hydrazide on plants. Bot. Gaz. 112:272-280.

Currier, H. B., K. Esau, and V. I. Cheadle

1955. Plasmolytic studies of phloem. Amer. Jour. Bot. 42:68-81.

DELWiChe, C. C., and J. WiJLER

1956. Non-symbiotic nitrogen fixation in soil. Plant and Soil 7:113-129.

Friesen, H. A., and D. R. WALKer

1954. Effect of herbicides on couch grass. Eleventh Annual North Central Weed Control Conf. Res. Rpt. 11:7.

Harris, V. C., W. S., Hardcastle, G. C. Kinngman, and S. V. Stacy

1954. Control of wild onion and garlic in winter pasture (and small grains). Seventh Annual Southern Weed Conf. Proc. 7:317.

Hoffman, O. L., and E. P. Sylwester

1ᄃ50. Effect of maleic hydrazide on devil's shoestring and quackgrass. Seventh Annual North Central Weed Control Conf. Res. Rpt. $7: 281$.

Levi, E., and A. S. CrafTS

1952. Toxicity of maleic hydrazide in California soils. Hilgardia 21(16):431-463.

Raleigh, S. M.

1955. Quackgrass control. Ninth Annual Northeastern Weed Control Conf. Res. Rept. 9:277-278.

Schcene, D. L., and O. L. Hofrman

1949. Maleic hydrazide, a unique growth regulant. Science 109:588-590.

VENGRIS, JONAS

1955. Quackgrass control in field corn by preplanting applications of maleic hydrazide and dalapon. Ninth Annual Northeastern Weed Control Conf. Proc. 9:399-400.

Weintraub, R. L., J. W. Brown, M. Fields, and J. Rohan

1952. Metabolism of 2,4-dichlorophenoxyacetic acid. I. $\mathrm{C}^{14} \mathrm{O}_{2}$ production by bean plants treated with labeled 2,4-dichlorophenoxyacetic acids. Plant Physiol. $27: 293-301$.

WiLKINSON, R. E.

1956. The physiological activity of 2,2-dichloropropionic acid. Unpublished doctoral dissertation. University of California, Davis.

Zick, W. H., and K. P. BuchHOLTZ

1954. Control of quackgrass with maleic hydrazide in combination with delayed plowing. Eleventh Annual North Central Weed Control Conf. Res. Rpt. 11:9.

ZUKEL, J. W.

1954. Literature summary on maleic hydrazide. MHIS No. 6B. Naugatuck Chemical Division, United States Rubber Co.

Zukel, J. W., A. E. Smith, G. M. Stone, and M. E. Davies

1956. Effect of some factors on rate of absorption of maleic hydrazide. Thirty-first Annual Meeting Amer. Soc. Plant Physiol. (Storrs, Conn.) Proc. Abstracted in Plant Physiol. 31(supp.):xxi. 

The journal Hilgardia is published at irregular intervals in volumes of about 600 pages. The number of issues per volume varies.

Subscriptions are not sold. The periodical is sent as published only to libraries, or to institutions in foreign countries having publications to offer in exchange.

You may obtain a single copy of any issue free, as long as the supply lasts; please request by volume and issue number from:

Agricultural Publications

Room 22, Giannini Hall

University of California

Berkeley 4, California

The limit to nonresidents of California is 10 separate issues on a single order. A list of the issues still available will be sent on request. 
